\title{
Chronic caffeine treatment disrupts the circadian rhythm in Drosophila
}

Aishwarya Segu and Nisha N Kannan*

Chronobiology Laboratory, School of Biology, Indian Institute of Science Education and

Research (IISER), Thiruvananthapuram, Kerala 695551, India

*Corresponding author. e-mail address: nishankannan@iisertvm.ac.in

Tel.: +0471-2778045; Fax: + 04712597427 


\begin{abstract}
The circadian clock governs the timing of sleep-wake cycles as well as of other behavioural, physiological and metabolic processes. While the endogenous circadian clock mediates the timing of sleep, homeostatic mechanisms modulate the amount and depth of sleep. Evidence from previous studies showed that caffeine intake promotes wakefulness, whereas adult-stage specific caffeine treatment not only suppresses sleep but also delays the phase of circadian rhythm in Drosophila. In humans, caffeine is consumed on a daily basis and hence it is important to understand the effect of prolonged caffeine intake on circadian and homeostatic regulation of sleep. In the present study we examined the differential effect of acute and chronic caffeine treatment on sleep ontogeny as well as on circadian and homeostatic regulation of sleep in Drosophila. The results of our study showed that acute caffeine treatment reduces day and night sleep in mature flies through the homeostatic pathway whereas it reduced only the day sleep in young flies. Chronic caffeine treatment did not exert any significant effect on sleep in young flies. On the other hand, it delayed the timing of sleep in mature flies and in addition flies under higher caffeine concentration reduced the morning and evening anticipatory activity under 12 hour: 12 hour light: dark cycles. These flies also exhibited either a longer free running period or arrhythmicity under constant darkness. The results of our study showed that acute caffeine treatment suppresses sleep through the homeostatic pathway whereas prolonged caffeine treatment disrupts the circadian rhythm in mature flies.
\end{abstract}

Keywords: caffeine, young, mature, acute, chronic, activity-rest rhythm, arrhythmicity 


\section{Statement of significance}

In the present study, we assessed the effect of caffeine on sleep ontogeny and circadian rhythm by using Drosophila as a model organism. We found that acute treatment of caffeine reduced sleep in both young and mature flies. Young flies were tolerant to chronic caffeine treatment whereas it affected the timing of sleep in mature flies. As in mammals, caffeine slows down the circadian clock in flies. Most importantly, prolonged caffeine treatment disrupted the circadian rhythm in Drosophila. Our studies provide new insights into the effect of prolonged daily caffeine intake on circadian clock and sleep.

\section{Introduction}

Sleep is a well-documented and conserved behavior that spans a wide range of organisms. Sleep is mediated by two physiological processes, the homeostatic process and the circadian clock $^{1-3}$. In Drosophila, the endogenous time keeping system consists of interlocked transcriptional-translational feedback loops (TTFLs) ${ }^{4}$. The transcription of the core clock genes period (per) and timeless (tim) is activated when the positive transcription factors CLOCK (CLK) and CYCLE (CYC) bind to their E-box promoters. PER and TIM protein heterodimers repress their own transcription by acting on CLK/CYC to release them from the E-box ${ }^{5-10}$. Circadian photoreceptor CRYPTOCHROME (CRY) governs light mediated degradation of TIM ${ }^{11,12}$ (Stanewsky et al. 1998; Dolezelova et al. 2007). Degradation of PER/TIM releases the transcriptional inhibition to initiate the next round of CLK-CYC mediated transcriptional activation and resets the clock. This feedback loop not only maintains the transcriptional rhythm, but 
also drives the activity/rest rhythm in Drosophila ${ }^{13}$. Under 12 hour: 12 hour (h) light: dark cycle (LD), flies exhibit bimodal activity patterns with a morning peak that coincides with lights-on and an evening peak before lights-off. Fruit flies exhibit a circadian pacemaker mediated gradual increase in anticipatory activity prior to lights-on and lights-off transitions ${ }^{14}$.

Studies in the recent past addressed the mechanisms by which circadian clocks govern the timing of sleep and the results showed that the circadian neuropeptide pigment-dispersing factor (PDF), diuretic hormone 31 (DH31), glutamate and $\mathrm{GABA}_{\mathrm{A}}$ receptor Resistant to dieldrin (RDL) expressed in subsets of circadian clock neurons in the fly brain mediate sleep and wakefulness to occur at the specific time of the day ${ }^{15-17}$. In addition, circadian output molecule WIDE AWAKE (WAKE) upregulates $\mathrm{GABA}_{\mathrm{A}}$ receptor RDL and reduces the excitability of clock neurons at the day/night transition to promote sleep onset ${ }^{18}$. The endogenous circadian clock regulates the timing of sleep whereas the homeostatic mechanisms modulate the depth, amount of sleep and allow the animals to recover sleep after the sleep loss ${ }^{19}$.

Behavioural, neurogenetic and physiological approaches dissected out the neural circuits involved in the homeostatic regulation of sleep. The results of these studies showed that mushroom bodies (MBs), ellipsoid body (EB) and dorsal fan-shaped body (dFSB) are the important brain centers mediating the homeostatic sleep drive in Drosophila $^{20-23}$. Dopaminergic signalling plays a key role in arousal and elevated dopamine reduces the sleep rebound indicating a role in sleep homeostasis ${ }^{24-26}$. Activation of dopamine receptors (dDA1) in the MBs rescues the effect of sleep loss on learning impairments ${ }^{27}$. 
Furthermore dDA1 in the MBs mediates the caffeine induced wakefulness in Drosophila $^{24}$. Caffeine promotes wakefulness by activating a cluster of dopaminergic neurons, the paired anterior medial (PAM) neurons in the fly brain ${ }^{28}$. Adult-stage specific caffeine treatment activates cAMP/PKA signalling in widespread areas of the brain to regulate sleep and lengthens the circadian period ${ }^{29}$. Although prior studies showed that caffeine suppresses sleep, it is important to understand the effect of prolonged daily caffeine consumption on circadian and homeostatic regulation of sleep. In the present study we examined the differential effect of acute and chronic caffeine treatment on sleep ontogeny as well as its impact on circadian and homeostatic regulation of sleep in Drosophila. The results of our study showed that acute caffeine treatment reduces sleep in both freshly emerged and mature flies whereas chronic treatment disrupts the circadian rhythm in mature flies.

\section{Materials and methodology}

Fly stock and maintenance

$w^{1118}$ flies were obtained from the Bloomington Drosophila Stock Centre (BDSC \#5905). All the flies were raised in standard cornmeal medium and were maintained at $25^{\circ} \mathrm{C}$ temperature, LD cycle where lights came on at Zeitgeber Time 00 (ZT00) and went off at ZT12 in the Drosophila growth chamber (Percival Scientific, Perry IA) with $65 \pm$ $5 \%$ humidity.

\section{Acute, chronic and adult stage specific caffeine treatment}

Standard cornmeal medium containing different concentrations of caffeine (Himedia) such as 0.0 (control), 0.5, 0.75 and $1 \mathrm{mg} / \mathrm{mL}$ were used for acute and chronic caffeine treatment. Day 1 (young) and Day 10 (mature) old flies were used in the acute 
and chronic caffeine treatment. For acute caffeine treatment, freshly emerged male flies were transferred to glass tubes containing cornmeal dextrose medium at ZT 12 on the day of emergence. On Day 1 prior to lights-on, these flies were flipped into glass tubes containing different concentrations of caffeine ranging from $0.0 \mathrm{mg} / \mathrm{mL}$ to $1 \mathrm{mg} / \mathrm{mL}$ and the locomotor activity was recorded for $24 \mathrm{~h}$ starting from ZT00 in MIR-154, Panasonic, Japan. To record the activity-rest rhythm of Day 10 old (mature) flies, on 9th day postemergence, male flies were transferred to the glass tubes containing cornmeal dextrose medium at ZT 12. On Day 10 prior to lights-on flies were flipped into glass tubes containing different concentrations of caffeine ranging from $0.0 \mathrm{mg} / \mathrm{mL}$ to $1 \mathrm{mg} / \mathrm{mL}$ and the locomotor activity was recorded for $24 \mathrm{~h}$ starting from ZT00.

For chronic caffeine treatment, the first instar larvae were reared in cornmeal medium containing different concentrations of caffeine (as mentioned above). Emerged flies were also maintained in the respective caffeine containing medium and the activityrest rhythm of young and mature flies were recorded in the glass tubes containing the cornmeal medium with the respective caffeine concentrations.

For the adult stage specific caffeine treatment, freshly emerged flies raised in standard cornmeal medium were transferred and maintained in cornmeal medium containing different caffeine concentrations (as mentioned above). Activity-rest rhythm of Day 2 and Day 10 flies were recorded in the glass tubes containing cornmeal medium with the respective caffeine concentrations.

\section{Sleep assay}

Young and mature male flies were individually introduced into glass tubes (65 $\mathrm{mm}$ length, $5 \mathrm{~mm}$ diameter) containing standard cornmeal medium with above mentioned 
concentrations of caffeine. Locomotor activity was recorded by using the Drosophila Activity Monitors (DAM, Trikinetics, USA) for 24h under LD. Flies were then transferred to non caffeinated medium after $24 \mathrm{~h}$ and the sleep rebound was recorded for the next 24h. 29-32 flies were used in each of the caffeine concentrations. Activity counts were measured at every 1 minute (min) interval and sleep was defined as 5 or more minutes of consolidated inactivity. Sleep parameters such as sleep latency, sleep bout length, sleep bout number, total sleep, day and night sleep were analysed using Sleep and Circadian Analysis MATLAB Program (SCAMP) $)^{30}$.

\section{Activity-rest assay}

Day 2 or Day 10 old male flies were individually introduced into locomotor activity glass tubes (65 mm length, $5 \mathrm{~mm}$ diameter) containing standard cornmeal medium with different concentrations of caffeine. Locomotor activity was recorded under LD for the initial 5 days and subsequently in constant darkness (DD) for 10 days to assess the free running period. The waveform of activity-rest rhythms under LD was obtained by dividing the activity data collected in every $1 \mathrm{~h}$ interval by the total amount of activity during the complete $24 \mathrm{~h}$ cycle. Anticipation index (AI) for lights-on and lightsoff was calculated as the ratio of activity in $3 \mathrm{~h}$ just prior to lights-on or lights-off to the activity that occurs $6 \mathrm{~h}$ before the transition ${ }^{31}$. The free running period of activity-rest rhythm was estimated by using the Lomb Scargle Periodogram of CLOCKLAB, Actimetrics, USA. For rhythmicity analysis, autocorrelation periodograms were constructed using raw activity count data $^{32}$ and rhythmicity index (RI) was calculated using VANESSA ${ }^{33}$. Flies were considered rhythmic if RI $>0.3$, weakly rhythmic if $0.1>\mathrm{RI}>0.3$ and arhythmic if $\mathrm{RI}<0.1 .28-32$ flies were used in each of the caffeine 
concentrations under LD condition whereas 80-90 flies were used for the DD experiments in chronic Day 10 and adult-stage specific Day 2 experiments. 56-60 flies were used for DD experiments in adult-stage specific Day 10 experiments.

\section{Pupation time assay}

50 first instar larvae were transferred into the vial containing either non-caffeinated or caffeinated food. Each biological replicate consisted of three such technical replicates. Average of three biological replicates were used to quantify the pupation time. Their pupation was assessed after the third instar larval stage for every 6 hours at ZT00, ZT06, ZT12 and ZT18, respectively.

\section{Statistical analysis}

One-way ANOVA or two-way ANOVA followed by post hoc Dunnett's or Sidak's HSD multiple comparisons was used respectively when data were normally distributed. For data sets that did not have a normal distribution, nonparametric MannWhitney's test or Kruskal-Wallis test followed by Dunn's post hoc multiple comparisons was used. The statistical analyses and sleep data analyses were performed using GraphPad PRISM version 9.2.0. Error bars in all the vertical bar graphs represent range and the error bars in the waveform of sleep, waveform of activity rest rhythm and percentage pupariation graph represents standard error of the mean (SEM).

\section{Results}

\section{Freshly emerged flies exhibit increased sleep than mature flies.}

Drosophila exhibit ontogenetic sleep changes ${ }^{34,35}$. To confirm the sleep ontogeny in Drosophila, we recorded activity-rest rhythm of Day 1 (young) and Day 10 (mature) $w^{1118}$ flies. Young flies exhibited a significant increase in both day (Mann-Whitney's test 
$p<0.001$ ) and night time sleep (Mann-Whitney's test $p<0.001$ ) resulting in higher total sleep compared to mature flies (Mann-Whitney's test $p<0.001$ ) (Figure 1A-D). These results confirm that young flies sleep more than mature flies.

\section{Effect of acute caffeine treatment on sleep ontogeny}

To examine the effect of caffeine on sleep ontogenetic changes, we recorded the activity-rest rhythm of young and mature $w^{1118}$ flies for 24 hours under cornmeal medium containing $0.0 \mathrm{mg} / \mathrm{mL}$ (control), $0.5 \mathrm{mg} / \mathrm{mL}, 0.75 \mathrm{mg} / \mathrm{mL}$ and $1 \mathrm{mg} / \mathrm{mL}$ concentrations of caffeine. Young flies under different concentrations of caffeine medium exhibited a decreased daytime sleep (Kruskal-Wallis followed by Dunn's multiple comparisons test; control vs $0.5 \mathrm{mg} / \mathrm{mL} p<0.008$, control v/s $0.75 \mathrm{mg} / \mathrm{mL} p<0.001$, control v/s $1 \mathrm{mg} / \mathrm{mL}$ $p<0.001$ ) (Figure 2B, 2C) resulting in a decreased total sleep compared to the control flies under cornmeal medium (Kruskal-Wallis test followed by Dunn's multiple comparisons test; control vs $0.5 \mathrm{mg} / \mathrm{mL} p<0.03$; control vs $0.75 \mathrm{mg} / \mathrm{mL} p<0.05$; control vs $1 \mathrm{mg} / \mathrm{mL} p<0.001$ ) (Figure $2 \mathrm{~B}, \mathrm{E}$ ). Acute caffeine treatment did not exert any significant effect on nighttime sleep in young flies (Figure 2D). To further check the quality of sleep due to caffeine ingestion, we calculated their sleep bout numbers and sleep bout length. A significant increase in sleep bout number (Kruskal-Wallis test followed by Dunn's multiple comparisons control v/s $0.5 \mathrm{mg} / \mathrm{mL} p<0.3$ ) and a significant decrease in sleep bout length was observed only under $0.5 \mathrm{mg} / \mathrm{mL}$ of caffeine treatment compared to the control (Kruskal-Wallis test followed by Dunn's multiple comparisons control v/s $0.5 \mathrm{mg} / \mathrm{mL} p<0.004$ ) (Figure S1A, B). We further analysed their sleep rebound (reb) to understand whether caffeine affects homeostatic sleep. Control flies exhibited a decrease in sleep on Day 2 compared to Day 1 (Kruskal-Wallis test control 
v/s control (reb) $p<0.005$ ) (Figure $2 \mathrm{H}, \mathrm{S} 1 \mathrm{C})$. Caffeine fed flies showed a significant increase in sleep rebound at $0.75 \mathrm{mg} / \mathrm{mL}$ and $1 \mathrm{mg} / \mathrm{mL}$ compared to the control (KruskalWallis Test followed by Dunn's multiple comparisons control v/s $0.75 \mathrm{mg} / \mathrm{mL} p<0.004$; control v/s $1 \mathrm{mg} / \mathrm{mL} p<0.001$ ) (Fig S1C). We were further interested in understanding if this sleep rebound was significantly different with respect to their sleep during the previous day of caffeine treatment. To do that we compared the rebound sleep with the sleep of respective caffeine treatment on the previous day and the results showed that the flies treated with $0.75 \mathrm{mg} / \mathrm{mL}$ and $1 \mathrm{mg} / \mathrm{mL}$ of caffeine concentrations exhibited an increased sleep rebound during the day (Kruskal-Wallis test followed by Dunn's multiple comparisons; $0.75 \mathrm{mg} / \mathrm{mL}$ v/s $0.75 \mathrm{mg} / \mathrm{mL}$ (reb) $p<0.001 \mathrm{mg} / \mathrm{mL}$ v/s $1 \mathrm{mg} / \mathrm{mL}$ (reb) $p<0.001$ ) (Figure 2F; Figure S1F-G) resulting in an increase in the total sleep rebound of these flies. (Kruskal-Wallis test $0.75 \mathrm{mg} / \mathrm{mL}$ vs $0.75 \mathrm{mg} / \mathrm{mL}$ (reb) $p<0.04 ; 1 \mathrm{mg} / \mathrm{mL}$ vs $1 \mathrm{mg} / \mathrm{mL}(\mathrm{reb}) p<0.001$ ) (Figure H; Figure S1F-G). Whereas the increase in night sleep rebound was observed only in $0.5 \mathrm{mg} / \mathrm{mL}$ and $1 \mathrm{mg} / \mathrm{mL}$ (Kruskal-Wallis test $0.5 \mathrm{mg} / \mathrm{mL}$ vs $0.5 \mathrm{mg} / \mathrm{mL}$ (reb) $p<0.05 ; 1 \mathrm{mg} / \mathrm{mL}$ vs $1 \mathrm{mg} / \mathrm{mL}$ (reb) $p<0.05$ ) (Figure $2 \mathrm{G}$, Fig S1E, G). These results suggest that higher concentrations of acute caffeine treatment affect the homeostatic sleep in young flies.

Next we moved on to understand the effect of acute exposure of caffeine on Day 10 old mature flies. These caffeine treated flies also exhibited a delay to fall asleep after lights-on resulting a significant reduction in daytime sleep (ANOVA followed by post hoc Sidak's multiple comparisons test; control vs $0.5 \mathrm{mg} / \mathrm{mL} p<0.001$; control vs 0.75 $\mathrm{mg} / \mathrm{mL} p<0.001$; control vs $1 \mathrm{mg} / \mathrm{mL} p<0.001$ ) (Figure $2 \mathrm{~J}, \mathrm{~K}$ ). In addition, these flies exhibited a reduction in night sleep at different concentrations of caffeine (Kruskal- 
Wallis followed by Dunn's multiple comparisons ; control vs $0.5 \mathrm{mg} / \mathrm{mL} p<0.05$; control vs $0.75 \mathrm{mg} / \mathrm{mL} p<0.001$; control vs $1 \mathrm{mg} / \mathrm{mL} p<0.001$ ) (Figure 2J, L) leading to decreased total sleep compared to control (Kruskal-Wallis followed by Dunn's multiple comparisons; control v/s $0.5 \mathrm{mg} / \mathrm{mL} p<0.001$; control v/s $0.75 \mathrm{mg} / \mathrm{mL} p<0.001$; control $\mathrm{v} / \mathrm{s} 1 \mathrm{mg} / \mathrm{mL} p<0.001$ ) (Figure $2 \mathrm{M}$ ). We further quantified their sleep bout numbers and found a significant increase only at $0.75 \mathrm{mg} / \mathrm{mL}$ (Kruskal-Wallis followed by Dunn's multiple comparisons; control v/s $0.75 \mathrm{mg} / \mathrm{mL} p<0.01$ ) but interestingly we found a decrease in sleep bout length in all caffeine concentrations compared to control (KruskalWallis followed by Dunn's multiple comparisons; control v/s $0.5 \mathrm{mg} / \mathrm{mL} p<0.04$; control v/s $0.75 \mathrm{mg} / \mathrm{mL} p<0.001$; control v/s $1 \mathrm{mg} / \mathrm{mL} p<0.001$ ) (Figure $\mathrm{S} 1 \mathrm{H}, \mathrm{I}$ ). This indicates that acute caffeine treatment on mature flies reduces sleep and also affects their quality of sleep. We also recorded the rebound sleep of caffeine treated flies and there was no significant difference when compared to the total sleep of control indicating that on removal of caffeine these flies get back to their normal sleep pattern (Figure S1C). We further analysed if this sleep rebound was significantly different with respect to their sleep during the previous day of caffeine treatment. A significant increase was observed in both the day (Kruskal-Wallis Test followed by Dunn's multiple comparisons 0.5 $\mathrm{mg} / \mathrm{mL} \mathrm{v} / \mathrm{s} 0.5 \mathrm{mg} / \mathrm{mL}$ (reb) $p<0.001 ; 0.75 \mathrm{mg} / \mathrm{mL} \mathrm{v} / \mathrm{s} 0.75 \mathrm{mg} / \mathrm{mL}$ (reb) $p<0.001 ; 1$ $\mathrm{mg} / \mathrm{mL} \mathrm{v} / \mathrm{s} 1 \mathrm{mg} / \mathrm{mL}(\mathrm{reb}) p<0.001$ ) and night sleep rebound (Kruskal-Wallis Test followed by Dunn's multiple comparisons $0.5 \mathrm{mg} / \mathrm{mL}$ v/s $0.5 \mathrm{mg} / \mathrm{mL}$ (reb) $p<0.001 ; 0.75$ $\mathrm{mg} / \mathrm{mL} \mathrm{v} / \mathrm{s} 0.75 \mathrm{mg} / \mathrm{mL}$ (reb) $p<0.001 ; 1 \mathrm{mg} / \mathrm{mL} \mathrm{v} / \mathrm{s} 1 \mathrm{mg} / \mathrm{mL}$ (reb) $p<0.001$ ) which was reflected as an increase in total sleep rebound (Kruskal-Wallis Test followed by Dunn's multiple comparisons $0.5 \mathrm{mg} / \mathrm{ml} \mathrm{v} / \mathrm{s} 0.5 \mathrm{mg} / \mathrm{ml} \mathrm{(reb)} p<0.001 ; 0.75 \mathrm{mg} / \mathrm{ml} \mathrm{v} / \mathrm{s} 0.75$ 
$\mathrm{mg} / \mathrm{mL}(\mathrm{reb}) p<0.001 ; 1 \mathrm{mg} / \mathrm{mL} \mathrm{v} / \mathrm{s} 1 \mathrm{mg} / \mathrm{mL}(\mathrm{reb}) p<0.001$ ) (Figure $2 \mathrm{~N}-\mathrm{P}$, Figure $\mathrm{S} 1 \mathrm{~J}-$ M ). These results suggest that acute caffeine treatment has an effect on the daytime sleep of freshly emerged flies whereas it reduces both the day and night sleep in mature flies through the sleep homeostatic pathway.

\section{Effect of chronic caffeine treatment on sleep ontogeny.}

Acute caffeine treatment reduced the sleep in Drosophila. However, in humans, caffeine is consumed on a daily basis. Hence we were interested to test the effects of prolonged caffeine consumption in Drosophila. To assess the effect of chronic caffeine treatment on sleep ontogeny, we reared the larvae under cornmeal medium containing different concentrations of caffeine namely $0.5,0.75$ and $1 \mathrm{mg} / \mathrm{mL}$. It was observed that pupation time increased with the increasing concentrations of caffeine from 0.75 to $1 \mathrm{mg} / \mathrm{mL}$ of caffeine (Kruskal Wallis followed by Dunn's multiple comparisons Control v/s $0.75 \mathrm{mg} / \mathrm{mL} p<0.04$; Control v/s $1 \mathrm{mg} / \mathrm{mL} p<0.003$ ) (Figure $\mathrm{S} 2 \mathrm{~B}, \mathrm{C}$ ). These results suggest that caffeine delays the pre-adult development in Drosophila. However we did not find any significant difference in the number of adult flies emerging under caffeine treatment compared to the control ( Data not shown).

After the emergence, the freshly emerged flies were still maintained under the respective caffeine medium and their activity-rest rhythm was also recorded under the respective caffeine concentrations. Surprisingly, freshly emerged flies under chronic caffeine treatment did not show any significant difference in total sleep compared to the control (Figure S2E, F). These flies did not show any significant difference in the sleep bout number and sleep bout length as well (Figure S2G, H). Mature flies under chronic caffeine treatment also did not exhibit any significant difference in total sleep compared 
to the control (Figure 3B, D), but interestingly a significant increase in day sleep was observed at $1 \mathrm{mg} / \mathrm{mL}$ caffeine concentration compared to the control (Kruskal Wallis followed by Dunn's multiple comparisons; control v/s $1 \mathrm{mg} / \mathrm{mL} p<0.005$ ) (Figure 3C). We further quantified the sleep bout length and found no significant difference but we found a decrease in the sleep bout number of $1 \mathrm{mg} / \mathrm{mL}$ caffeine treated flies when compared to control (Kruskal-Wallis followed by Dunn's multiple comparisons; control $\mathrm{v} / \mathrm{s} 1 \mathrm{mg} / \mathrm{mL} p<0.05$ ) (Figure $\mathrm{S} 2 \mathrm{~J}, \mathrm{~K}$ ). As there was a visible delay in sleep offset (Figure 3D) during the transition from day to night in caffeine fed flies, we quantified their sleep latency but it was not significantly different from the control (Figure S2L). However, chronic caffeine treatment prolonged the siesta even after the lights-off. As it was the siesta offset which was prolonged we further quantified the sleep at ZT03-04 and ZT11-12. $1 \mathrm{mg} / \mathrm{mL}$ of caffeine treated flies exhibited a decrease in sleep at ZT03-04 (Kruskal-Wallis test followed by Dunn's multiple comparisons; control v/s $0.75 \mathrm{mg} / \mathrm{mL}$ $p<0.01$ ) (Figure S2M) whereas an increase in sleep during ZT11-12 was observed in all the three different concentrations of caffeine treated flies compared to the control (Kruskal-Wallis test followed by Dunn's multiple comparisons control v/s $0.5 \mathrm{mg} / \mathrm{mL}$ $p<0.05$; control v/s $0.75 \mathrm{mg} / \mathrm{mL} p<0.004$; control v/s $1 \mathrm{mg} / \mathrm{mL} p<0.001$ ) (Figure $3 \mathrm{E}$ ). These results suggest that chronic caffeine treatment affects the timing of siesta offset in mature flies leading us to further investigate the effect of chronic caffeine treatment on circadian clock.

\section{Chronic caffeine treatment alters the anticipatory activity and the free running periodicity.}

To study the effect of chronic caffeine treatment on circadian rhythm, we 
examined the effect of chronic caffeine treatment on activity-rest rhythm under LD in Day 10 (mature) flies. The results showed that $0.5 \mathrm{mg} / \mathrm{ml}$ of caffeine treatment decreased activity at ZT11, ZT12 and increased the activity at ZT14 (Figure 3G) (Table S1), whereas $0.75 \mathrm{mg} / \mathrm{mL}$ of chronic caffeine treatment showed increased activity at ZT 02 , ZT13, ZT14 and decreased activity at ZT00 (Figure 3H) (Table S1). $1 \mathrm{mg} / \mathrm{mL}$ of caffeine treatment showed decreased activity at ZT23, ZT00, ZT01, ZT11, ZT12 and increased activity ZT03, ZT04, ZT14 and ZT15 (Figure 3I) (Table S1). This change in the activity prior to light-on and lights-off indicate that there could be a change in morning and evening anticipatory activity. To confirm this we quantified their morning and evening anticipation index and the flies treated with $1 \mathrm{mg} / \mathrm{mL}$ of caffeine showed significant decrease in both the morning and evening anticipation index compared to the control (Kruskal-Wallis test followed by Dunn's multiple comparisons, morning anticipation index control v/s $1 \mathrm{mg} / \mathrm{mL} p<0.001$; evening anticipation index $p<0.001$ ) (Figure $3 \mathrm{~J}-\mathrm{K}$ ). These results indicate that higher concentration of chronic caffeine treatment may affect the endogenous clock rhythmicity. To test this we recorded their activity-rest rhythm under DD and it was observed that caffeine treatment lengthened the free running periodicity compared to the control (Figure 4B-J). Apart from showing a longer free running periodicity, some flies also exhibited arrhythmicity. $93.4 \%$ of flies were rhythmic in the case of control whereas only $81.8 \%$ of flies were rhythmic under $0.5 \mathrm{mg} / \mathrm{mL}$ of caffeine caffeine treatment with a longer mean free running periodicity (Kruskal-Wallis Test followed by Dunn's multiple comparisons; control v/s $0.5 \mathrm{mg} / \mathrm{mL}$ $p<0.001)$ and rest $18.2 \%$ of the flies exhibited arrhythmicity. $81.9 \%$ of flies were rhythmic under $0.75 \mathrm{mg} / \mathrm{mL}$ of caffeine caffeine treatment with a longer mean free 
running periodicity (Kruskal-Wallis Test followed by Dunn's multiple comparisons; control v/s $0.75 \mathrm{mg} / \mathrm{mL} p<0.001)$ and the rest of the flies exhibited arrhythmicity. $37.5 \%$ of flies exhibited a longer mean free running periodicity (Kruskal-Wallis Test followed by Dunn's multiple comparisons; control v/s $1 \mathrm{mg} / \mathrm{mL} p<0.001$ ) and $62.5 \%$ of flies were arrhythmic under $1 \mathrm{mg} / \mathrm{ml}$ of chronic caffeine treatment (Figure 4I). We also measured their rhythmicity index and it was observed that as the caffeine concentration increases more and more flies exhibit either arrhythmicity or a longer free running periodicity (Figure 4I, J) suggesting that higher concentrations of chronic caffeine treatment disrupts the endogenous rhythmicity in mature flies.

\section{Effect of adult-stage specific caffeine treatment on circadian rhythm}

To understand whether the effect of chronic caffeine treatment on circadian rhythm is development stage or adult-stage specific, we provided caffeine treatment only in an adult-stage specific manner and assessed its effect on sleep in Day 10 (mature) flies. $0.75 \mathrm{mg} / \mathrm{mL}$ and $1 \mathrm{mg} / \mathrm{mL}$ of caffeine treated flies prolonged the siesta even after the lights-off resulted in significant increase of day sleep compared to the control (KruskalWallis Test followed by Dunn's multiple comparisons; control v/s $0.75 \mathrm{mg} / \mathrm{mL} p<0.007$; control v/s $1 \mathrm{mg} / \mathrm{mL} p<0.007$ ) (Figure 5B, E). The significant increase observed in total sleep of $0.75 \mathrm{mg} / \mathrm{mL}$ and $1 \mathrm{mg} / \mathrm{mL}$ of caffeine treated flies (Kruskal-Wallis Test followed by Dunn's multiple comparisons; control v/s $0.75 \mathrm{mg} / \mathrm{mL} p<0.003$; control v/s $1 \mathrm{mg} / \mathrm{mL}$ $p<0.01)$ were only from the increase of day sleep and not from night sleep indicating that these results are similar to the results obtained under chronic caffeine treatment (Figure 5B, D, E). To confirm this we further quantified the sleep at ZT03-04 and ZT11-12. The results showed that flies treated with $0.75 \mathrm{mg} / \mathrm{mL}$ and $1 \mathrm{mg} / \mathrm{mL}$ of caffeine showed a 
decrease in sleep from ZT03-04 (Kruskal-Wallis Test followed by Dunn's multiple comparisons; control v/s $0.75 \mathrm{mg} / \mathrm{mL} p<0.001$; control v/s $1 \mathrm{mg} / \mathrm{mL} p<0.001$ ) (Figure 5F) whereas flies under all the different caffeine concentrations showed an increase in sleep at ZT11-12 compared to the control (Kruskal-Wallis Test followed by Dunn's multiple comparisons; control v/s $0.5 \mathrm{mg} / \mathrm{mL} p<0.001$; control v/s $0.75 \mathrm{mg} / \mathrm{mL} p<0.001$; control v/s $1 \mathrm{mg} / \mathrm{mL} p<0.001$ ) (Figure 5G). Similar to the results obtained under chronic caffeine treatment we did not find any significant difference in the sleep bout length and we found a decrease in the sleep bout number of $1 \mathrm{mg} / \mathrm{mL}$ caffeine treated flies when compared to control (Kruskal-Wallis followed by Dunn's multiple comparisons; control $\mathrm{v} / \mathrm{s} 1 \mathrm{mg} / \mathrm{mL} p<0.003$ ) (Figure $5 \mathrm{H}, \mathrm{I}, \mathrm{S} 2 \mathrm{~J}, \mathrm{~K}$ ). These results suggest that adult caffeine treatment affects the timing of mid day sleep offset in mature flies just like the chronic treatment (Figure 3E, 5G).

Further to assess the effect of adult-stage specific caffeine treatment on circadian rhythm, we examined the effect of adult-stage specific caffeine treatment on activity-rest rhythm under LD in mature (Day 10) flies. The results showed that $0.5 \mathrm{mg} / \mathrm{mL}$ of caffeine treated flies showed increase in activity at ZT14 (Figure 5K) (Table S2), whereas $0.75 \mathrm{mg} / \mathrm{mL}$ of caffeine treated flies showed decrease in activity at ZT00, ZT12 and an increase in activity at ZT14 and ZT15 (Figure 5L) (Table S2). $1 \mathrm{mg} / \mathrm{mL}$ of caffeine treated flies showed decrease in activity at ZT00, ZT01, ZT11, ZT12, ZT13 and an increase in activity at ZT03 and ZT14 (Figure 5M) (Table S2). This altered activity during the morning and evening hours indicates that there could be a change in the morning and evening anticipatory activity. To confirm this we quantified their morning anticipation index which showed no significant difference (Figure $5 \mathrm{~N}$ ) whereas evening 
anticipation index showed a significant decrease under $1 \mathrm{mg} / \mathrm{mL}$ of caffeine treatment compared to the control (Kruskal-Wallis test followed Dunn's multiple comparisons control v/s $1 \mathrm{mg} / \mathrm{mL} p<0.001$ ) (Figure 5O).

To assess the effect of adult-stage specific caffeine treatment on endogenous clocks, we recorded free running periodicity of mature flies treated with caffeine in adult-stage specific manner. Similar to the results obtained under chronic treatment, adult-stage specific caffeine treatment led to either longer free-running periodicity (Kruskal-Wallis Test followed by Dunn's multiple comparisons; control v/s $0.5 \mathrm{mg} / \mathrm{mL}$ $p<0.001$; control v/s $0.75 \mathrm{mg} / \mathrm{mL} p<0.001$; control v/s $1 \mathrm{mg} / \mathrm{mL} p<0.001$ ) (Figure 5P) or arrhythmicity (Figure 5Q). These results suggest that effects of chronic caffeine treatment on circadian rhythm in mature flies is mainly arising from the adult-stage specific caffeine treatment.

\section{Effect of prolonged caffeine treatment is not age dependent in Drosophila}

In most of our experiments we used Day 10 old mature flies to test the effect of prolonged caffeine treatment on circadian rhythm. In order to assess whether the effect of caffeine on circadian rhythm is an age specific effect, we provided adult-stage specific caffeine treatment and recorded the activity of Day 2 old flies. All the three concentrations of caffeine treatment decreased the activity at ZT 10-12 and increased the activity at ZT13. In addition $1 \mathrm{mg} / \mathrm{mL}$ of caffeine treatment decreased the morning peak of activity and the activity prior to lights on (Figure S3 B-D) (Table S3). We quantified the morning and evening anticipation index and caffeine treated flies did not exhibit any significant difference in morning anticipation index whereas $1 \mathrm{mg} / \mathrm{mL}$ of caffeine treated flies exhibited a decrease in the evening anticipation index compared to the control 
(Kruskal-Wallis Test followed Dunn's multiple comparisons control v/s $1 \mathrm{mg} / \mathrm{mL}$ $p<0.001$ ) (Figure S3E, F). Following this we assessed the free running periodicity of Dasy 2 old flies under DD. The free running period of caffeinated flies is significantly increased when compared to the control (Kruskal-Wallis Test followed by Dunn's multiple comparisons; control v/s $0.5 \mathrm{mg} / \mathrm{mL} p<0.001$; control v/s $0.75 \mathrm{mg} / \mathrm{mL} p<0.001$; control v/s $1 \mathrm{mg} / \mathrm{mL} p<0.001$ ) (Figure $\mathrm{S} 3 \mathrm{G}$ ). We also measured their rhythmicity index and it was observed that arrhythmicity increases with increasing concentrations of caffeine (Figure $\mathrm{S} 3 \mathrm{H}$ ). These results suggest that the effect of prolonged caffeine ingestion on circadian rhythm is not age dependent and is also not dependent on the duration of caffeine treatment in adult flies.

\section{Discussion}

Caffeine fragments the sleep and promotes wakefulness in Drosophila ${ }^{29,36}$. Dopamine signalling is involved in the arousal promoting effect of caffeine. Caffeine promotes wakefulness by promoting the activity of paired anterior medial (PAM) clusters of dopaminergic neurons ${ }^{28}$. The dopaminergic neural circuit also governs the sleep ontogenetic changes in Drosophila ${ }^{34}$. Subset of dopaminergic neurons with projections to the dorsal fan-shaped body is hypoactive in freshly emerged flies and this reduced dopamine signalling leads to increased sleep in young flies compared to the mature flies ${ }^{34}$. In the present study we confirmed that young flies sleep more compared to mature flies and assessed the effect of acute caffeine treatment on sleep ontogeny. Acute caffeine treatment reduces the day time sleep in freshly emerged flies. On the other hand, it reduces both the day and night time sleep in mature flies indicating the differential effect of caffeine on homeostatic sleep of both mature and young flies. It is important to 
identify the mechanisms through which acute caffeine administration affects the sleep ontogeny. It is likely that the effect of caffeine on dopamine signalling could account for this differential effect observed in young and mature flies. Further studies are required to understand whether caffeine interacts with the hypoactive dopamine circuits in young flies or if any other complex mechanism is contributing to this behavioural output.

Caffeine mediated behavioural output seems to be dependent on the duration of caffeine administration $^{37,38}$. For instance, animals rapidly develop tolerance to caffeineinduced locomotor activity under chronic caffeine administration ${ }^{39}$. We assessed the effect of chronic caffeine treatment on sleep ontogeny and the results showed that young flies under different concentrations of chronic caffeine treatment did not show any significant difference in sleep compared to the controls indicating that freshly emerged flies probably developed tolerance to chronic caffeine treatment. Mature flies under different concentrations of chronic caffeine treatment exhibited a delay in the onset of day time sleep and it prolonged even after the lights-off indicating that chronic caffeine treatment may affect the circadian rhythm in mature flies.

Taken together these results showed the divergent effect of acute and chronic caffeine treatment on sleep of young and mature flies. This differential effect of acute and chronic caffeine treatment on sleep ontogeny supports the notion that different mechanisms may be involved in the acute and chronic caffeine treatment mediated sleep changes of young and mature flies. In a previously reported study, low doses of caffeine $(0.1,0.2$ and $0.5 \mathrm{mg} / \mathrm{mL})$ was provided over a period of two days in 5-8 day old wild-type caffeine sensitive strain $R C 1$ flies. This low doses of adult-stage specific chronic caffeine administration decreased the sleep and lengthened the free running periodicity ${ }^{29}$. 
Furthermore caffeine lengthens the free running periodicity in Neurospora crassa and mice $^{40,41}$. The effect of caffeine on behavioural output not only depends on the duration of caffeine intake but also appears to be dependent on concentration of caffeine ${ }^{37}$. The results of our present study shows that long term administration of higher concentrations of caffeine in mature flies reduces the morning and evening anticipatory activity under LD. With increasing caffeine concentration, flies exhibited either longer free running periodicity or arrhythmicity under DD. However chronic caffeine administration has no impact on freshly emerged flies or they were tolerant to caffeine whereas it impacts the endogenous clock of mature flies supporting the notion that fundamentally different mechanisms may be at play in young and mature flies on exposure to chronic caffeine treatment.

It has been previously reported that caffeine can phase delay or advance the electrical activity rhythm in the isolated $\mathrm{SCN}$ from hamster and rat brain ${ }^{42,43}$. These findings suggest that caffeine may influence the circadian timing system. In the mammalian circadian pacemaker, caffeine acts primarily through the Adenosine receptor A1 and thus modulates cAMP signalling, the core component of cellular circadian clock $^{44-46}$. However adult-stage specific caffeine treatment mediated wakefulness was shown to be independent of adenosine receptor in Drosophila and enhanced cAMP/PKA signalling is partly involved in this adult stage specific caffeine mediated wakefulness ${ }^{29}$. Nevertheless we cannot exclude the possibility that caffeine acts on additional relevant targets to affect the circadian timing in Drosophila. Further studies are required to understand whether caffeine modulates the cAMP signalling in clock neurons or any other underlying mechanism through which caffeine affects the circadian clock in 


\section{Drosophila.}

Our study also showed that chronic caffeine treatment delays the pre-adult development in Drosophila. Caffeine treatment in the early stages of development alters the Adenosine receptor mRNA expression levels and adenosine signalling through adenosine receptor orchestrates the pre-adult development in Drosophila ${ }^{47,48}$. In the present study we showed the effect of $0.5 \mathrm{mg} / \mathrm{ml}, 0.75 \mathrm{mg} / \mathrm{ml}$ and $1 \mathrm{mg} / \mathrm{ml}$ of caffeine on circadian rhythm in Drosophila. Previous studies showed that low doses $(0.1,0.2$ and $0.5 \mathrm{mg} / \mathrm{mL}$ ) of adult-stage specific caffeine treatment to wild-type caffeine sensitive strain RC1 decreases sleep in Drosophila ${ }^{29}$. In the present study we tested the effect of $0.25 \mathrm{mg} / \mathrm{ml}$ of caffeine treatment on sleep homeostasis and circadian rhythm and we did not find any significant difference compared to the control (data not shown). This could be probably due to the fact that in our study we used $w^{1118}$ male flies. Higher concentrations of chronic and adult-stage specific caffeine treatment led to a marginal increase in the lethality of Day 10 old mature flies during the activity-rest rhythm assays. Hence we also confirmed that the effect of higher concentration of caffeine on circadian rhythm is even present in Day 2 old flies and this effect of caffeine on circadian clock is not age dependent in Drosophila.

In summary, the results of our studies showed that acute caffeine treatment reduces the day time sleep in young flies whereas it decreases both day and night time sleep in mature flies. While chronic caffeine treatment does not have an effect on the sleep of young flies, it delays the onset of day time sleep in mature flies. In addition, chronic caffeine treatment disrupts the circadian rhythm in Drosophila. 


\section{Acknowledgements}

We thank Dr. Jishy Varghese for the valuable suggestions and Jervis Fernandes for the experimental assistance. This work was supported by the DBT/Wellcome Trust India Alliance Fellowship [IA/E/15/1/502329] awarded to NNK and intramural fund from Indian Institute of Science Education and Research, Thiruvananthapuram.

\section{Disclosure statements}

Financial disclosure: none.

Non-financial disclosure: none. 


\section{References}

1. Tricoire H, Artiushin G, Zhang S, Tricoire H, Sehgal A. Endocytosis at the Drosophila blood-brain barrier as a function for sleep. eLife, 2018;2918; 7.

2. Allada R, Cirelli C, Sehgal A. Molecular mechanisms of sleep homeostasis in flies and mammals. Cold Spring Harbor perspectives in biology, 2017; 9(8), a027730.

3. Dubowy C, Sehgal A. Circadian Rhythms and Sleep in Drosophila melanogaster. Genetics. 2017;205(4):1373-1397. doi:10.1534/genetics.115.185157

4. Hardin PE. Molecular genetic analysis of circadian timekeeping in Drosophila. $A d v$ Genet. 2011;74:141-173. doi:10.1016/B978-0-12-387690-4.00005-2

5. Konopka RJ, Benzer S. Clock Mutants of Drosophila melanogaster. Proc Natl Acad Sci. 1971;68(9):2112-2116. doi:10.1073/pnas.68.9.2112

6. Sehgal A, Price JL, Man B, Young MW. Loss of circadian behavioral rhythms and per RNA oscillations in the Drosophila mutant timeless. Science. 1994;263(5153):1603-1606. doi:10.1126/science.8128246

7. Allada R, White NE, So WV, Hall JC, Rosbash M. A mutant Drosophila homolog of mammalian Clock disrupts circadian rhythms and transcription of period and timeless. Cell. 1998;93(5), 791-804.

8. Rutila JE, Suri V, Le M, So WV, Rosbash M, Hall JC. CYCLE is a second bHLHPAS clock protein essential for circadian rhythmicity and transcription of Drosophila period and timeless. Cell. 1998;93(5):805-814. doi:10.1016/s0092$8674(00) 81441-5$

9. Benito J, Zheng H, Ng FS, Hardin PE. Transcriptional feedback loop regulation, function and ontogeny in Drosophila. Cold Spring Harb Symp Quant Biol. 
2007;72:437-444. doi:10.1101/sqb.2007.72.009

10. Hardin PE. Molecular mechanisms of circadian timekeeping in Drosophila. Sleep Biol Rhythms. 2009;7(4):235-242. doi:10.1111/j.1479-8425.2009.00412.x

11. Stanewsky R, Kaneko M, Emery P, Beretta B, Wager-Smith K, Kay SA, Hall JC et.al. The cryb mutation identifies cryptochrome as a circadian photoreceptor in Drosophila. Cell. 1998;95(5), 681-692.

12. Dolezelova E, Dolezel D, Hall JC. Rhythm defects caused by newly engineered null mutations in Drosophila's cryptochrome gene. Genetics. 2007;177(1):329-345. doi:10.1534/genetics.107.076513

13. Taghert PH, Shafer OT. Mechanisms of clock output in the Drosophila circadian pacemaker system. $J$ Biol Rhythms. 2006;21(6):445-457. doi:10.1177/0748730406293910

14. Stoleru D, Peng Y, Agosto J, Rosbash M. Coupled oscillators control morning and evening locomotor behaviour of Drosophila. Nature. 2004;431(7010):862-868. doi:10.1038/nature02926

15. Agosto J, Choi JC, Parisky KM, Stilwell G, Rosbash M, Griffith LC. Modulation of GABAA receptor desensitization uncouples sleep onset and maintenance in Drosophila. Nat Neurosci. 2008;11(3):354-359. doi:10.1038/nn2046

16. Kunst M, Hughes ME, Raccuglia D, Felix M, Li M, Barnett G, Duah J et al. Calcitonin gene-related peptide neurons mediate sleep-specific circadian output in Drosophila. Current Biology, 2014; 24(22), 26522664.doi:10.1016/j.cub.2014.09.077

17. Guo F, Yu J, Jung HJ, Abruzzi KC, Luo W, Griffith LC, Rosbash M. Circadian 
neuron feedback controls the Drosophila sleep--activity profile. Nature. 2016;536(7616):292-297. doi:10.1038/nature19097

18. Liu S, Lamaze A, Liu Q, Tabuchi M, Yang Y, Fowler M, Bharadwaj R et al. WIDE AWAKE mediates the circadian timing of sleep onset. Neuron. 2014;82(1):151-166. doi:10.1016/j.neuron.2014.01.040

19. Borbély AA, Achermann P. Sleep homeostasis and models of sleep regulation. $J$ Biol Rhythms. 1999;14(6):557-568. doi:10.1177/074873099129000894

20. Liu S, Liu Q, Tabuchi M, Wu MN. Sleep Drive Is Encoded by Neural Plastic Changes in a Dedicated Circuit. Cell. 2016;165(6):1347-1360. doi:10.1016/j.cell.2016.04.013

21. Joiner WJ, Crocker A, White BH, Sehgal A. Sleep in Drosophila is regulated by adult mushroom bodies. Nature. 2006;441(7094):757-760. doi:10.1038/nature04811

22. Pitman JL, McGill JJ, Keegan KP, Allada RA dynamic role for the mushroom bodies in promoting sleep in Drosophila. Nature, 2006; 441(7094), 753-756.

23. Liu Q, Liu S, Kodama L, Driscoll MR, Wu MN. Two Dopaminergic Neurons Signal to the Dorsal Fan-Shaped Body to Promote Wakefulness in Drosophila. Curr Biol. 2012;22(22):2114-2123. doi:10.1016/j.cub.2012.09.008

24. Andretic R, van Swinderen B, Greenspan RJ. Dopaminergic modulation of arousal in Drosophila. Curr Biol CB. 2005;15(13):1165-1175. doi:10.1016/j.cub.2005.05.025

25. Kume K, Kume S, Park SK, Hirsh J, Jackson FR. Dopamine Is a Regulator of Arousal in the Fruit Fly. $J$ Neurosci. 2005;25(32):7377-7384. doi:10.1523/JNEUROSCI.2048-05.2005 
26. Wu MN, Koh K, Yue Z, Joiner WJ, Sehgal A. A Genetic Screen for Sleep and Circadian Mutants Reveals Mechanisms Underlying Regulation of Sleep in Drosophila. Sleep. 2008;31(4):465-472.

27. Seugnet L, Suzuki Y, Vine L, Gottschalk L, Shaw PJ. D1 receptor activation in the mushroom bodies rescues sleep-loss-induced learning impairments in Drosophila. Curr Biol CB. 2008;18(15):1110-1117. doi:10.1016/j.cub.2008.07.028

28. Nall AH, Shakhmantsir I, Cichewicz K, Birman S, Hirsh J, Sehgal A. Caffeine promotes wakefulness via dopamine signaling in Drosophila. Sci Rep. 2016;6(1):20938. doi:10.1038/srep20938

29. Wu MN, Ho K, Crocker A, Yue Z, Koh K, Sehgal A. The effects of caffeine on sleep in Drosophila require PKA activity, but not the adenosine receptor. Journal of Neuroscience, 2009;29(35), 11029-11037.

30. Donelson N, Kim EZ, Slawson JB, Vecsey CG, Huber R, Griffith LC. HighResolution Positional Tracking for Long-Term Analysis of Drosophila Sleep and Locomotion Using the "Tracker" Program. PLOS ONE. 2012;7(5):e37250. doi:10.1371/journal.pone.0037250

31. Harrisingh $\mathrm{MC}, \mathrm{Wu} \mathrm{Y}$, Lnenicka GA, Nitabach MN. Intracellular Ca2+ regulates free-running circadian clock oscillation in vivo. $J$ Neurosci Off $J$ Soc Neurosci. 2007;27(46):12489-12499. doi:10.1523/JNEUROSCI.3680-07.2007

32. Selcho M, Millán C, Palacios-Muñoz A, et al. Central and peripheral clocks are coupled by a neuropeptide pathway in Drosophila. Nat Commun. 2017;8(1):15563. doi:10.1038/ncomms 15563

33. Arijit Ghosh. (2021,). orijitghosh/VANESSA-DAM: Experimental release of 
VANESSA v1.0.0 (Version v1.0.0). Zenodo.http://doi.org/10.5281/zenodo.4781020

Repository link: https://github.com/orijitghosh/VANESSA-DAM

34. Kayser MS, Yue Z, Sehgal A. A critical period of sleep for development of courtship circuitry and behavior in Drosophila. Science. 2014;344(6181):269-274. doi:10.1126/science. 1250553

35. Dilley LC, Vigderman A, Williams CE, Kayser MS. Behavioral and genetic features of sleep ontogeny in Drosophila. Sleep. 2018;41(7). doi:10.1093/sleep/zsy086

36. Andretic R, Kim Y-C, Jones FS, Han K-A, Greenspan RJ. Drosophila D1 dopamine receptor mediates caffeine-induced arousal. Proc Natl Acad Sci U S A. 2008;105(51):20392-20397. doi:10.1073/pnas.0806776105

37. Ferré S. An update on the mechanisms of the psychostimulant effects of caffeine. $J$ Neurochem. 2008;105(4):1067-1079. doi:10.1111/j.1471-4159.2007.05196.x

38. Jacobson KA, von Lubitz DK, Daly JW, Fredholm BB. Adenosine receptor ligands: differences with acute versus chronic treatment. Trends Pharmacol Sci. 1996;17(3):108-113. doi:10.1016/0165-6147(96)10002-х

39. Finn IB, Holtzman SG. Tolerance to caffeine-induced stimulation of locomotor activity in rats. J Pharmacol Exp Ther. 1986;238(2):542-546.

40. Feldman JF. Circadian Periodicity in Neurospora: Alteration by Inhibitors of Cyclic AMP Phosphodiesterase. $\quad$ Science. 1975;190(4216):789-790. doi:10.1126/science. 173018

41. Oike H, Kobori M, Suzuki T, Ishida N. Caffeine lengthens circadian rhythms in mice. Biochem Biophys Res Commun. 2011;410(3):654-658. doi:10.1016/j.bbrc.2011.06.049 
42. Ding JM, Buchanan GF, Tischkau SA, et al. A neuronal ryanodine receptor mediates light-induced phase delays of the circadian clock. Nature. 1998;394(6691):381-384. doi:10.1038/28639

43. Díaz-Muñoz M, Dent MA, Granados-Fuentes D, et al. Circadian modulation of the ryanodine receptor type 2 in the SCN of rodents. Neuroreport. 1999;10(3):481-486. doi:10.1097/00001756-199902250-00007

44. O’Neill JS, Maywood ES, Chesham JE, Takahashi JS, Hastings MH. cAMPdependent signaling as a core component of the mammalian circadian pacemaker. Science. 2008;320(5878):949-953. doi:10.1126/science.1152506

45. Jagannath A, Varga N, Dallmann R, et al. Adenosine integrates light and sleep signalling for the regulation of circadian timing in mice. Nat Commun. 2021;12(1):2113. doi:10.1038/s41467-021-22179-Z

46. Burke TM, Markwald RR, McHill AW, Chinoy ED, Snider JA, Bessman SC, Wright Jr KP. et al. Effects of caffeine on the human circadian clock in vivo and in vitro. Sci. Trans. Med. 2015; 7.

47. Dolezal T, Dolezelova E, Zurovec M, Bryant PJ. A Role for Adenosine Deaminase in Drosophila Larval Development. PLOS Biol. 2005;3(7):e201. doi:10.1371/journal.pbio.0030201

48. Francikowski J, Baran B, Płachetka-Bożek A, Krzyżowski M, Augustyniak M. Caffeine effects on AdoR mRNA expression in Drosophila melanogaster. Open Life Sci. 2016;11(1):244-249. doi:10.1515/biol-2016-0034 


\section{Figure Legend}

Figure 1. Sleep ontogeny in Drosophila. (A) Sleep in minutes (min) for every $30 \mathrm{~min}$ over a period of $24 \mathrm{~h}$ under $12 \mathrm{~h}: 12 \mathrm{~h}$ light dark cycle (LD) is shown for Day 1 (young) and Day 10 old (mature) $w^{1118}$ flies. (B-D) Day, night and total sleep in min for Day 1 (young) and Day 10 old (mature) $w^{1118}$ flies. Young flies exhibited increased sleep than mature flies. Error bars are SEM for the sleep profile and error bars in the vertical bar graphs represent range.

Figure 2. Effect of acute caffeine treatment on sleep ontogeny. (A) Schematic showing the experimental design of acute caffeine treatment for Day 1 (young) flies. The horizontal line indicates the life cycle of Drosophila. The vertical bar represents the emergence of the fly. The yellow vertical line indicates the starting of locomotor activity recording. The induction of caffeine is indicated by the green triangle and the red triangle indicates the removal of caffeine. Caffeine was provided for $24 \mathrm{~h}$ during the locomotor activity recording. (B) Sleep in min for every 30 min over a period of $24 \mathrm{~h}$ under LD cycle is shown for Day 1 old (young) $w^{1118}$ flies of control, $0.5 \mathrm{mg} / \mathrm{mL}, 0.75$ $\mathrm{mg} / \mathrm{mL}$ and $1 \mathrm{mg} / \mathrm{mL}$ of acute caffeine treatment. (C-E) Quantified day, night and total sleep in min for Day 1 old (young) $w^{1118}$ flies with acute caffeine treatment. Young flies exhibited a significant reduction in daytime sleep under different caffeine concentrations compared to the control. Rebound sleep was measured following the caffeine treatment for $24 \mathrm{~h}$, which was divided into $(\mathrm{F})$ day sleep , (G) night sleep $(\mathrm{H})$ compiled as total sleep for $24 \mathrm{~h}$. Flies treated with different caffeine concentrations experienced an increased sleep rebound compared to the total sleep during the previous day of caffeine treatment. (I) Schematic showing the experimental design of acute caffeine treatment in Day 10 old 
(mature) flies. The horizontal line indicates the life cycle of Drosophila and the vertical bar indicates emergence of the fly. The yellow vertical line indicates the start of activity recording. The induction of caffeine is indicated by the green triangle and the red triangle indicates removal of caffeine. (J) Sleep in min for every 30 min over a period of $24 \mathrm{~h}$ under LD cycle is shown for Day 10 old (mature) $w^{1118}$ flies with $0.5 \mathrm{mg} / \mathrm{mL}, 0.75$ $\mathrm{mg} / \mathrm{mL}$ and $1 \mathrm{mg} / \mathrm{mL}$ of acute caffeine treatment. (K-M) Quantified day, night and total sleep in min for Day 10 old mature flies with acute treatment of caffeine concentrations ranging from $0.5 \mathrm{mg} / \mathrm{mL}-1 \mathrm{mg} / \mathrm{mL}$ along with the control. Caffeine treated mature flies exhibited a significant reduction in both daytime and nighttime sleep compared to the control. (N-P) Rebound sleep was measured in mature flies following the caffeine treatment for $24 \mathrm{~h}$, which was divided into $(\mathrm{N})$ day sleep , $(\mathrm{O})$ night sleep $(\mathrm{P})$ compiled as total sleep for 24h. Mature flies treated with different caffeine concentrations experienced an increased sleep rebound during both day and night compared to their sleep during the previous day of caffeine treatment. All other details are the same as in Figure 1.

\section{Figure 3. Effect of chronic caffeine treatment on sleep ontogeny}

(A) Schematic showing the experimental design of chronic caffeine treatment in Day 10 mature flies. Caffeine was provided from the development of the first instar larval stage indicated by green triangle till the completion of the locomotor activity recording on Day 10. All other details are the same as in Figure 2A. (B) Sleep in min for every 30 min over a period of $24 \mathrm{~h}$ under LD cycle is shown for Day 10 old (mature) $w^{1118}$ flies with $0.5 \mathrm{mg} / \mathrm{mL}, 0.75 \mathrm{mg} / \mathrm{mL}$ and $1 \mathrm{mg} / \mathrm{mL}$ of chronic caffeine treatment. (C, D) Day time and 
total sleep in min for Day 10 old mature flies with chronic treatment of caffeine concentrations ranging from $0.5 \mathrm{mg} / \mathrm{mL}-1 \mathrm{mg} / \mathrm{mL}$ along with the control. No significant difference was observed in the total sleep between control and caffeine treated flies. However flies treated with $1 \mathrm{mg} / \mathrm{mL}$ of caffeine exhibited an increase in day sleep compared to the control (E) Sleep of Day 10 old (mature) $w^{1118}$ flies at ZT11-12 under chronic caffeine treatment ranging from $0.5 \mathrm{mg} / \mathrm{mL}-1 \mathrm{mg} / \mathrm{mL}$ along with the control. Chronic caffeine treated mature flies exhibited enhanced sleep at ZT11-12 compared to the control. (F) Schematic showing the experimental design of chronic caffeine treatment to assay the activity-rest rhythm of Day 10 old mature flies. The black horizontal line represents the life cycle of Drosophila. The first vertical line represents the emergence of the fly and the second vertical bar represents the change in experimental conditions from LD to DD. All other details are the same as in Figure 3A. (G-I) The percentage activity of Day 10 old mature flies under $0.5 \mathrm{mg} / \mathrm{mL}, 0.75 \mathrm{mg} / \mathrm{mL}$ and $1 \mathrm{mg} / \mathrm{mL}$ of chronic caffeine treatment. The percentage of activity averaged over 5 consecutive cycles is plotted along the $y$-axis and Zeitgeber Time in hours along the $x$-axis. The grey shaded and empty areas respectively represent the duration of light and darkness in the LD cycle. $(\mathrm{J}, \mathrm{K})$ Anticipation to lights-on and lights-off is plotted for the flies under $0.5 \mathrm{mg} / \mathrm{ml}, 0.75 \mathrm{mg} / \mathrm{ml}$ and $1 \mathrm{mg} / \mathrm{ml}$ of chronic caffeine treatment. Flies exhibited a significant reduction in morning and evening anticipatory activity at $1 \mathrm{mg} / \mathrm{mL}$ of caffeine concentrations. All other details are the same as in Figure 2.

Figure 4. Chronic caffeine treatment disrupts the endogenous circadian rhythmicity of mature flies. (A) Schematic showing the experimental design of chronic caffeine treatment to assay the free running periodicity of Day 10 old mature flies. All the details 
are the same as Figure 3F. (B-H) Representative actograms of mature flies with chronic treatment of caffeine concentrations ranging from $0.5 \mathrm{mg} / \mathrm{mL}-1 \mathrm{mg} / \mathrm{mL}$ along with the control. As the caffeine concentration increases flies exhibit either longer free running periodicity or arrhythmicity under DD. (I) Mean free running periodicity of flies that are rhythmic under different caffeine concentrations. Only those flies exhibited rhythmicity under different caffeine concentrations were selected for this analysis. Numbers given in italics on top of the bar graph represent the percentage of rhythmic flies. While $93.4 \%$ of control flies exhibited rhythmicity, only $37.5 \%$ of flies exhibited rhythmicity under $1 \mathrm{mg} / \mathrm{ml}$ of caffeine. Higher caffeine concentration slows down the pace of the circadian clock. (J) Rhythmicity index of mature flies under chronic treatment of caffeine with concentrations ranging from $0.5 \mathrm{mg} / \mathrm{mL}$ along with the control. All the flies that were alive post 6 days of DD recording were pooled here for the rhythmicity index analysis. Rhythmicity index values between 0.3 and above were considered to be rhythmic, 0.3 to 0.2 as weakly rhythmic and values below 0.2 as arrhythmic. As the caffeine concentration increased more and more flies became arrhythmic under DD. The grey criss-cross lines in each vertical bar indicate the absence of flies for analysis. All other details are the same as in Figure 2.

Figure 5 Adult stage specific caffeine treatment disrupts the circadian rhythmicity of mature flies. (A) Schematic showing the experimental design of adult-stage specific caffeine treatment to assay the sleep of Day 10 old mature flies. Caffeine was provided to Day 0 freshly emerged flies till Day 10 until the completion of the locomotor activity recording for 24h. All the details are the same as in Figure 2A. (B) Sleep in min for every 30 min over a period of $24 \mathrm{~h}$ under LD cycle is shown for Day 10 old (mature) 
$w^{1118}$ flies with $0.5 \mathrm{mg} / \mathrm{mL}, 0.75 \mathrm{mg} / \mathrm{mL}$ and $1 \mathrm{mg} / \mathrm{mL}$ of adult-stage specific caffeine treatment. (C-E) Day, night and total sleep in min for Day 10 old mature flies with $0.5 \mathrm{mg} / \mathrm{mL}, 0.75 \mathrm{mg} / \mathrm{mL}$ and $1 \mathrm{mg} / \mathrm{mL}$ of chronic caffeine treatment compared with the control. $0.75 \mathrm{mg} / \mathrm{mL}$ and $1 \mathrm{mg} / \mathrm{mL}$ of caffeine treated flies exhibited increased day time sleep resulting in an increase in total sleep compared to the control. (F, G) Sleep of Day 10 old mature flies at ZT03-04 and ZT11-12 of $0.5 \mathrm{mg} / \mathrm{mL}, 0.75 \mathrm{mg} / \mathrm{mL}$ and $1 \mathrm{mg} / \mathrm{mL}$ of chronic caffeine treatment compared with the control. Adult-stage specific caffeine treated flies exhibited reduced sleep at ZT03-04 and increased sleep at ZT11-12 compared to the control. (H, I) Sleep bout number and sleep bout length of Day 10 old mature flies under different concentrations of adult-stage specific caffeine treatment. A significant increase in sleep bout number was observed only under $0.75 \mathrm{mg} / \mathrm{mL}$ of caffeine treatment compared to the control. (J) Schematic showing the experimental design of adult-stage specific caffeine treatment for measuring activity-rest rhythm. All the details are the same as in Figure 3F except that caffeine treatment was started only after emergence and was provided till the completion of locomotor activity recording. (K-M) The percentage activity of Day 10 old mature flies from 0.5 to $1 \mathrm{mg} / \mathrm{mL}$ of adultstage specific caffeine treatment compared with the control. The percentage of activity averaged over 5 consecutive cycles is plotted along the $y$-axis and Zeitgeber Time in hours along the $x$-axis. The grey shaded and empty areas respectively represent the duration of darkness and light in the LD cycle. (N, O) Anticipation to lights-on and lights-off is plotted for the flies with adult-stage specific caffeine treatment from 0.5 to $1 \mathrm{mg} / \mathrm{mL}$ of adult-stage specific caffeine treatment compared to the control. Flies treated with $1 \mathrm{mg} / \mathrm{mL}$ of caffeine exhibit increased evening anticipation index compared to the 
control. (P) Mean free running periodicity of mature flies that are rhythmic under different concentrations of adult-stage specific caffeine treatment. Only those flies exhibited rhythmicity under different caffeine concentrations were selected for this analysis. Numbers given in italics above the vertical bar graph represent the percentage of rhythmic flies. Higher caffeine concentration lengthens the free running period. (Q) Rhythmicity index of mature flies under different concentrations of adult-stage specific caffeine treatment. RI values between 0.3 and above were considered to be rhythmic, 0.3 to 0.2 as weakly rhythmic and values below 0.2 as arrhythmic. As the caffeine concentration increases more and more flies become arrhythmic under DD, the grey criss cross lines in each vertical bar indicate absence of flies for analysis. All other details are the same as in Figure 4.

Figure S1. (A, B) Sleep bout number and sleep bout length of Day 1 (young) flies under different concentrations of acute caffeine treatment. A significant increase in sleep bout number and a significant decrease in sleep bout length was observed only under 0.5 $\mathrm{mg} / \mathrm{mL}$ of caffeine treatment compared to the control. (C) Sleep rebound (reb) of Day 1 (young) and Day 10 (mature) flies after the acute caffeine treatment. Young control flies exhibited a decrease in sleep on Day 2 compared to Day 1. Caffeine fed young flies showed a significant increase in sleep rebound at $0.75 \mathrm{mg} / \mathrm{mL}$ and $1 \mathrm{mg} / \mathrm{mL}$ compared to the control. Mature flies did not exhibit any significant difference in sleep rebound compared to the control. (D-G) Comparison of rebound sleep of acute caffeine treated Day 1 (young) flies with their sleep during the previous day of caffeine treatment. $(\mathrm{H}, \mathrm{I})$ Sleep bout number and sleep bout length of Day 10 (mature) flies under different concentrations of acute caffeine treatment. A significant decrease in sleep bout length 
was observed under acute caffeine treatment compared to the control. (J-M) Comparison of rebound sleep of acute caffeine treated Day 10 mature flies with their sleep during the previous day of caffeine treatment. All other details are the same as in Figure 2.

Figure S2. (A) Schematic showing the experimental design to assess the effect of chronic caffeine treatment on pupation time. The horizontal line indicates the larval phase of the Drosophila life cycle with the vertical lines indicating the 3 different larval stages namely 1 st instar $(1 *), 2$ nd instar $(2 *)$ and 3 rd instar $(3 *)$. The yellow line indicates the starting of pupation. $(\mathrm{B}, \mathrm{C})$ Percentage of pupation and mean pupation time in hours under different concentrations of chronic caffeine treatment. (D) Schematic showing the experimental design of chronic caffeine treatment in young flies. All the details are the same as in Figure 3A. (E) Sleep in min for every 30 min over a period of $24 \mathrm{~h}$ under LD cycle is shown for day 1 old (young) $w^{1118}$ flies with $0.5 \mathrm{mg} / \mathrm{mL}, 0.75 \mathrm{mg} / \mathrm{mL}$ and 1 $\mathrm{mg} / \mathrm{mL}$ of chronic caffeine treatment. (F) Total sleep in min for Day 1 (young) $w^{1118}$ flies with $0.5 \mathrm{mg} / \mathrm{ml}, 0.75 \mathrm{mg} / \mathrm{ml}$ and $1 \mathrm{mg} / \mathrm{ml}$ of chronic caffeine treatment. Young flies did not exhibit any significant difference in total sleep between the control and caffeine treated flies. $(\mathrm{G}, \mathrm{H})$ Sleep bout number and sleep bout length of Day 1 old flies under different concentrations of chronic caffeine treatment. No significant difference was observed in the sleep bout number and sleep bout length of chronic caffeine treated Day 1 old flies compared to the control. (I) Schematic showing the experimental design of chronic caffeine treatment in Day 10 old mature flies. All the details are the same as in Figure 3A. (J, K) Sleep bout number and sleep bout length of Day 10 old (mature) flies under different concentrations of chronic caffeine treatment. No significant difference was observed in the sleep bout length and a significant increase in sleep bout number was 
observed only in $1 \mathrm{mg} / \mathrm{mL}$ of chronic caffeine treated Day 10 old (mature) flies compared to the control. (L) Sleep latency of Day 10 old mature flies with $0.5 \mathrm{mg} / \mathrm{mL}, 0.75 \mathrm{mg} / \mathrm{mL}$ and $1 \mathrm{mg} / \mathrm{mL}$ of chronic caffeine treatment. No significant difference was observed in sleep latency between the control and chronic caffeine treated flies. (M) Sleep of Day 10 old (mature) $w^{1118}$ flies at ZT03-04 of control, $0.5 \mathrm{mg} / \mathrm{mL}, 0.75 \mathrm{mg} / \mathrm{mL}$ and $1 \mathrm{mg} / \mathrm{mL}$ of chronic caffeine treatment. $1 \mathrm{mg} / \mathrm{mL}$ of chronic caffeine treated flies exhibited reduced sleep at ZT03-04 compared to the control.

Figure S3. (A) Schematic showing the experimental design of adult-stage specific caffeine treatment for measuring the activity-rest rhythm of Day 2 old flies. All other details are the same as in Figure 5J except that caffeine treatment was started from Day 0 freshly emerged flies and was provided only till 16th day until the completion of the locomotor activity under DD. The locomotor activity started under LD from Day 2- Day 6 and subsequently flies were transferred to DD to assess the free running periodicity. (B-D) The percentage activity of Day 2 old flies under $0.5 \mathrm{mg} / \mathrm{mL}, 0.75 \mathrm{mg} / \mathrm{mL}$ and 1 $\mathrm{mg} / \mathrm{mL}$ of adult-stage specific caffeine treatment compared with the control. The percentage of activity averaged over 5 consecutive cycles is plotted along the $y$-axis and Zeitgeber Time in hours along the $x$-axis. The grey shaded and empty areas respectively represent the duration of darkness and light in the LD cycle. (E, F) Anticipation to lightson and lights-off is plotted for the Day 2 old flies under $0.5 \mathrm{mg} / \mathrm{mL}, 0.75 \mathrm{mg} / \mathrm{mL}$ and 1 $\mathrm{mg} / \mathrm{mL}$ of adult-stage specific caffeine treatment compared to the control. Flies treated with $1 \mathrm{mg} / \mathrm{mL}$ of caffeine exhibit increased evening anticipation index compared to the control. (G) Mean free running periodicity of Day 2 old flies that are rhythmic under different concentrations of adult-stage specific caffeine treatment. Higher caffeine 
concentration lengthened the free running periodicity of Day 2 old flies. Only those flies exhibiting rhythmicity under different caffeine concentrations were selected for this analysis. Numbers given in italics above the vertical bar graph represent the percentage of rhythmic flies. (H) Rhythmicity index of Day 2 old flies treated with $0.0 \mathrm{mg} / \mathrm{mL}$, $0.5 \mathrm{mg} / \mathrm{mL}, 0.75 \mathrm{mg} / \mathrm{mL}$ and $1 \mathrm{mg} / \mathrm{mL}$ of caffeine concentrations in an adult-stage specific manner. As the caffeine concentration increases more and more flies become arrhythmic under DD. All other details are the same as in Figure 5. 
A bioRxiv preprint doi: httpsid/dpi.org/10. B 1/2021.10.08.463733; this vers posted October 9, 2021. The cDyright holder for this preprint (which was not certified by peer review) is the author/funder, who has granted bioRxiv a license to display the preprint in perpetuity. It is made
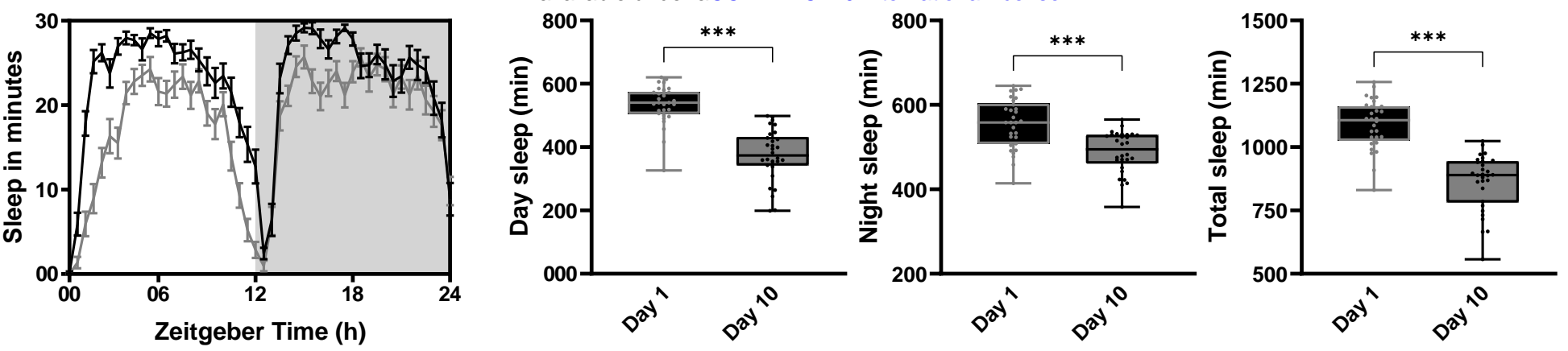


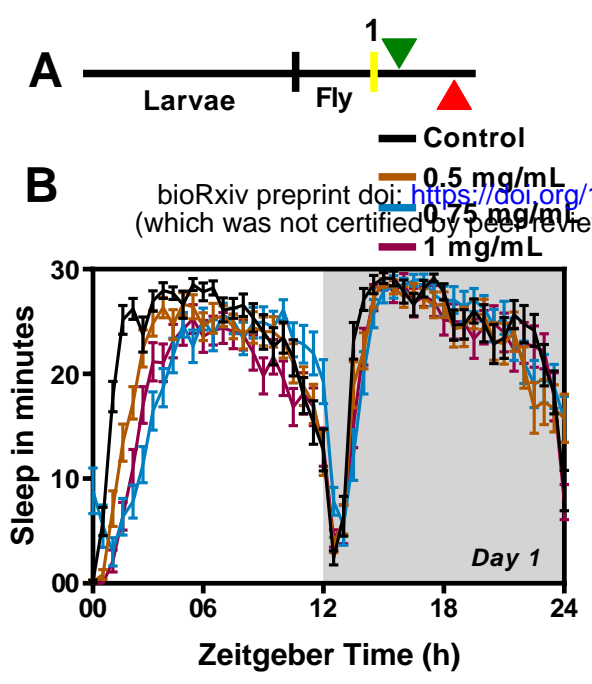

F

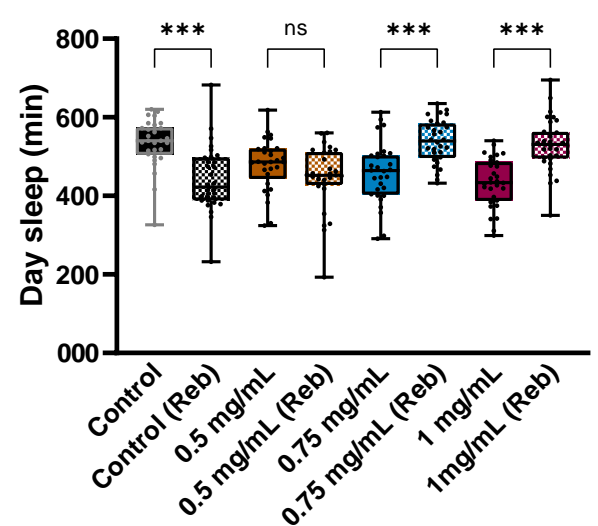

Caffeine concentrations

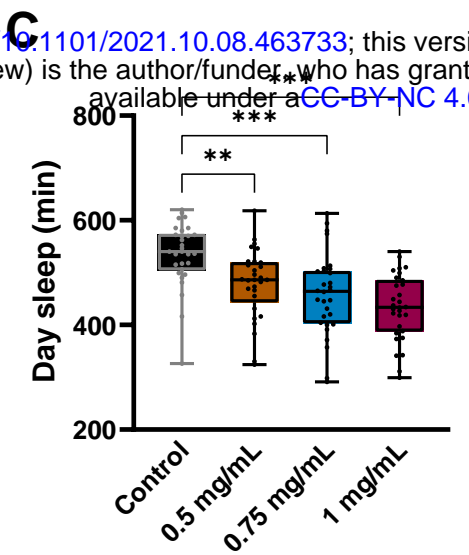

Caffeine concentrations

G

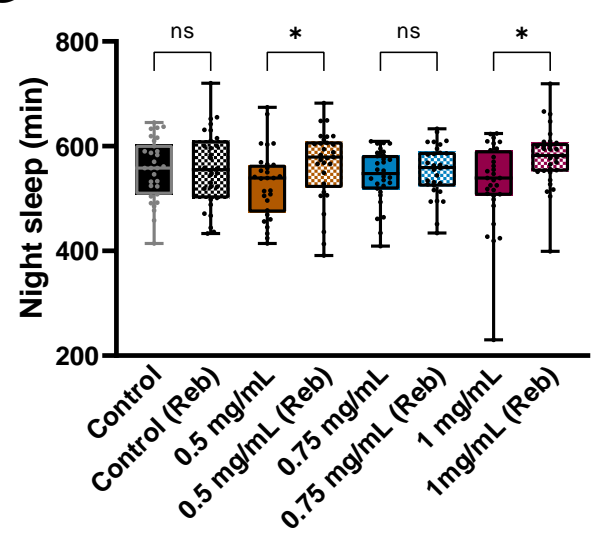

Caffeine concentrations

E

posted October $9 s 2021$. The copyright holder for this preprint

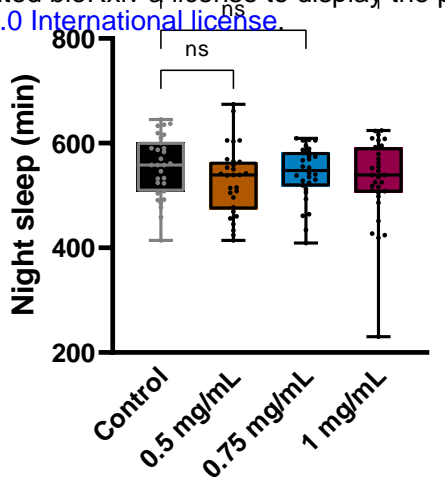

Caffeine concentrations

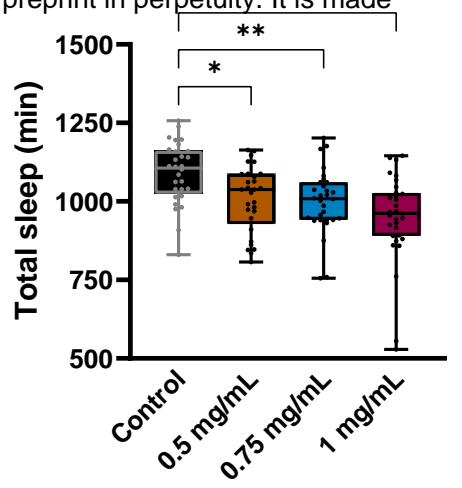

Caffeine concentrations

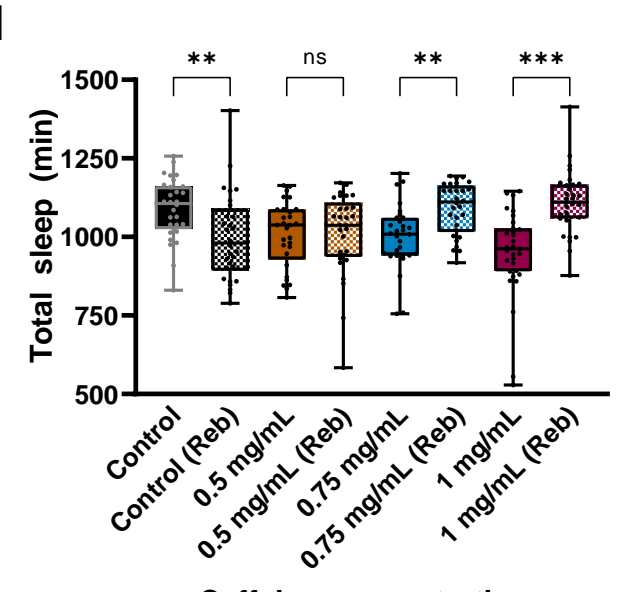

Caffeine concentrations

H

10
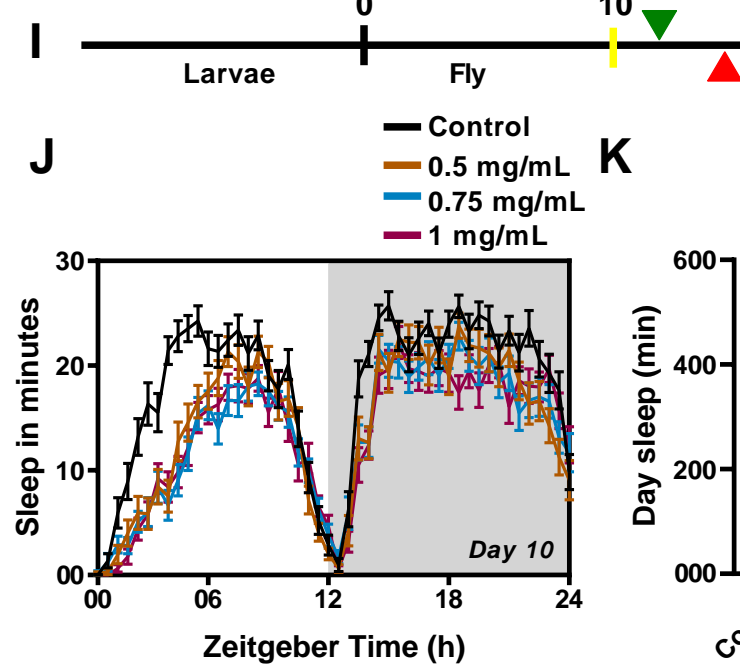

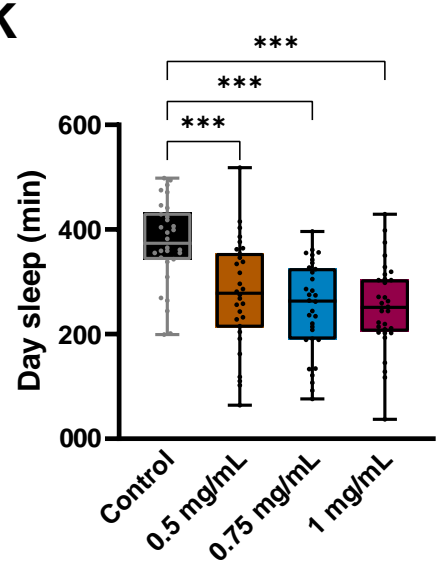

Caffeine concentrations
$\mathbf{L}$

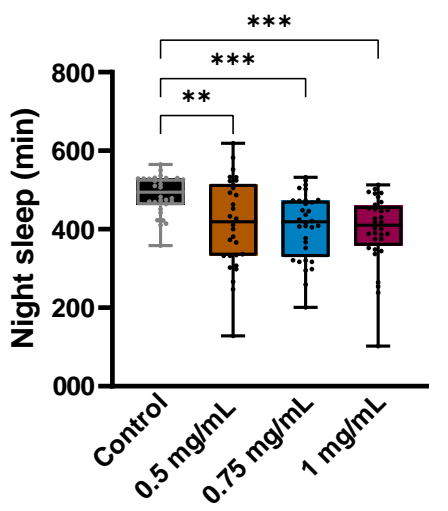

Caffeine concentrations
M

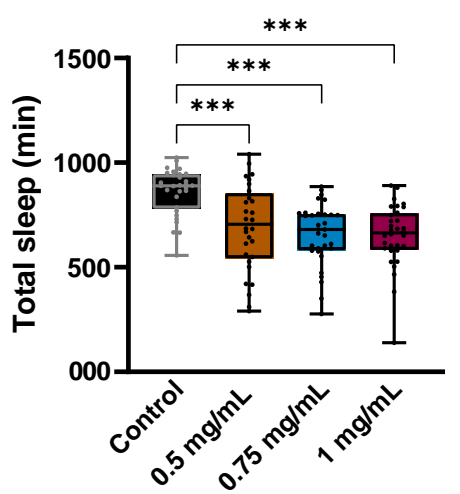

Caffeine concentrations

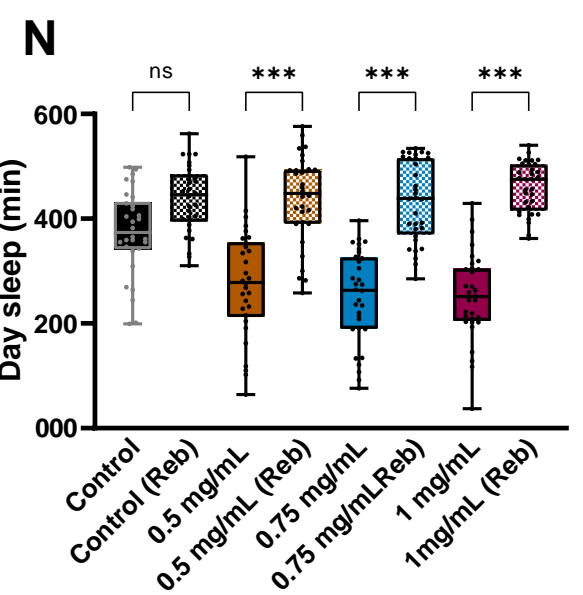

Caffeine concentrations
0

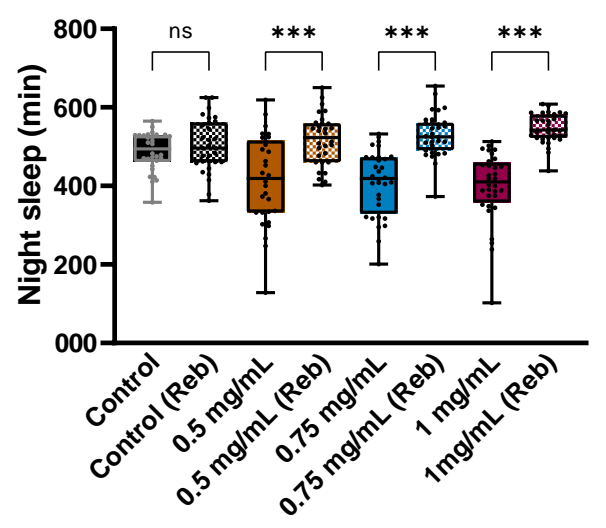

Caffeine concentrations

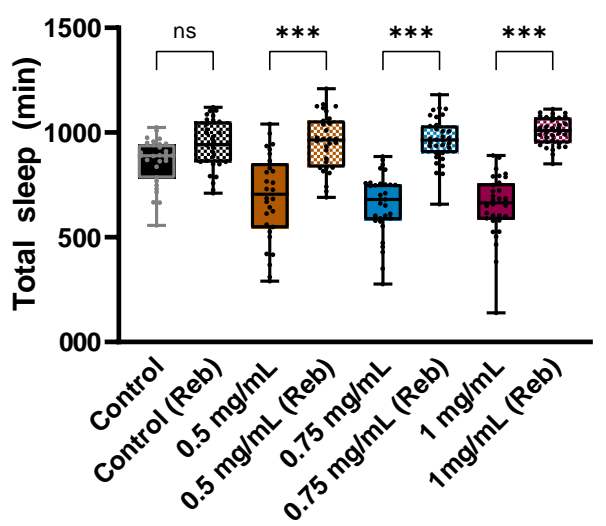

Caffeine concentrations 
A

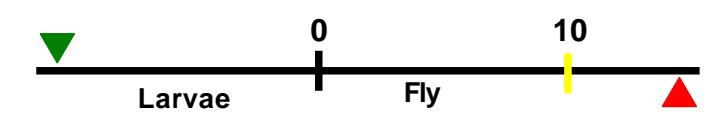

- Control

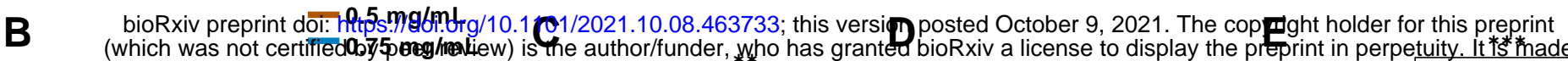
(which was not certifiedoby 50 hiew) is the author/funder, who has granted bioRxiv a license to display the preprint in perpetuity. It *s thade

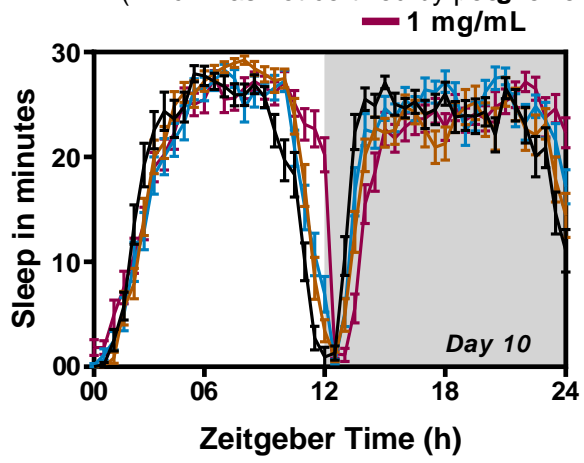

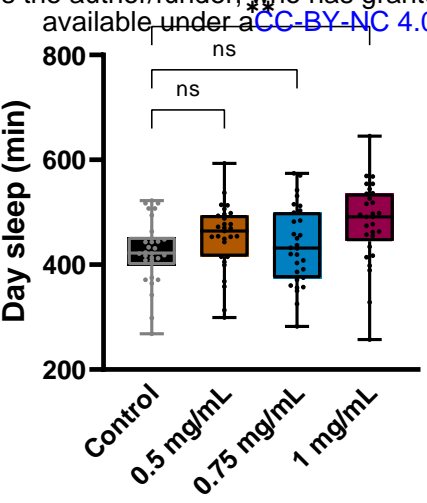

Caffeine concentrations

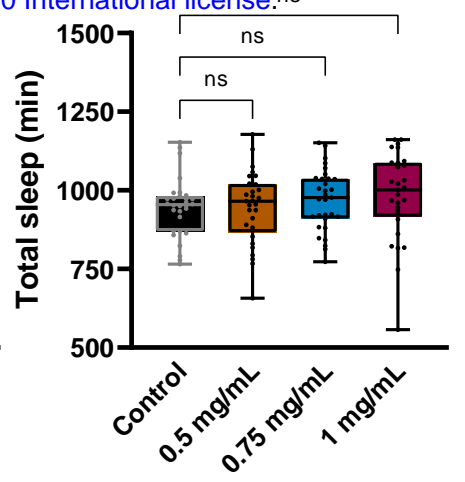

Caffeine concentrations

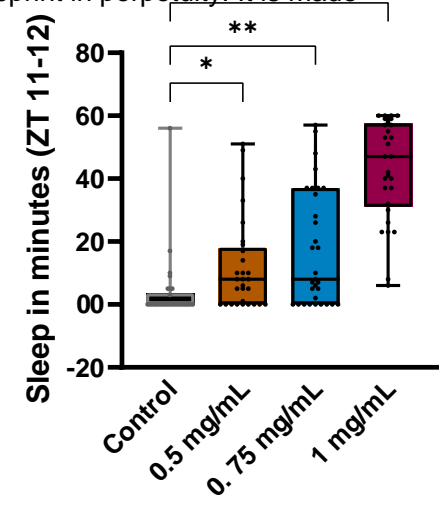

Caffeine concentrations

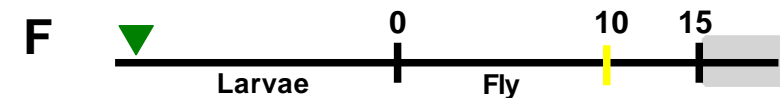

G

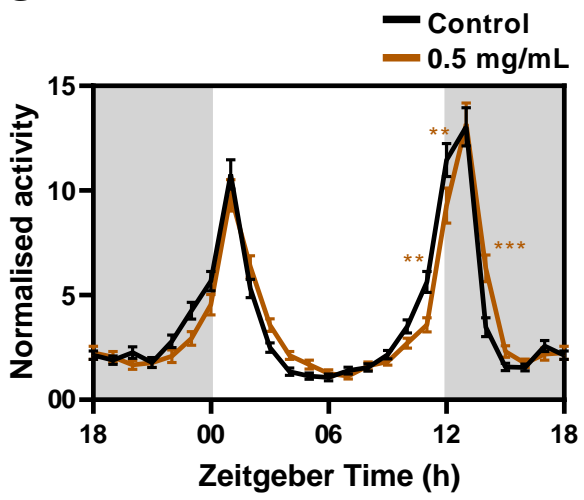

H

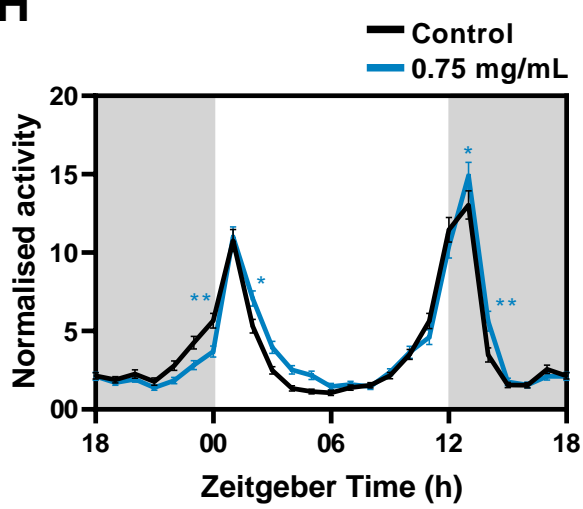

Figure 3

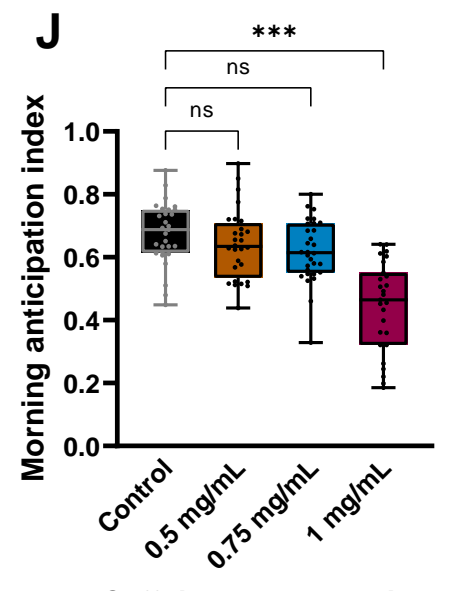

Caffeine concentrations

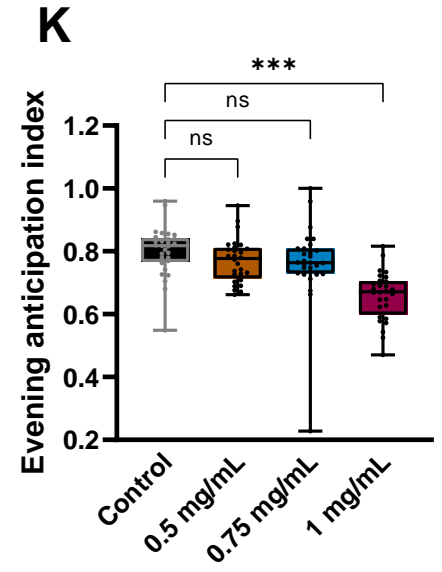

Caffeine concentrations
I

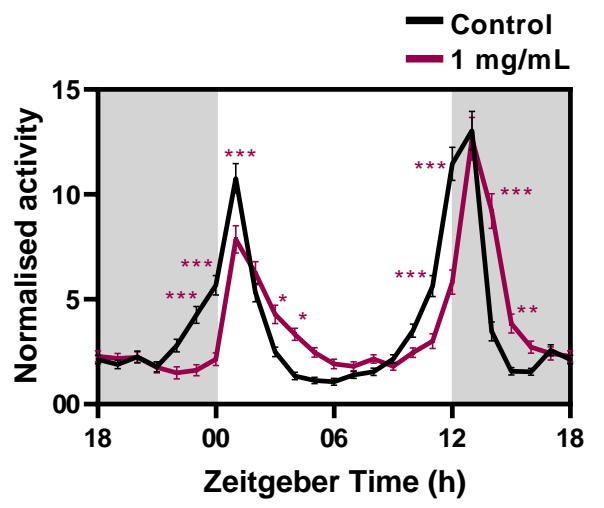




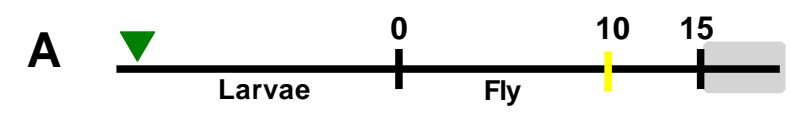

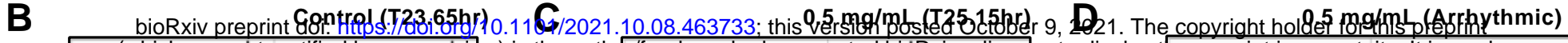

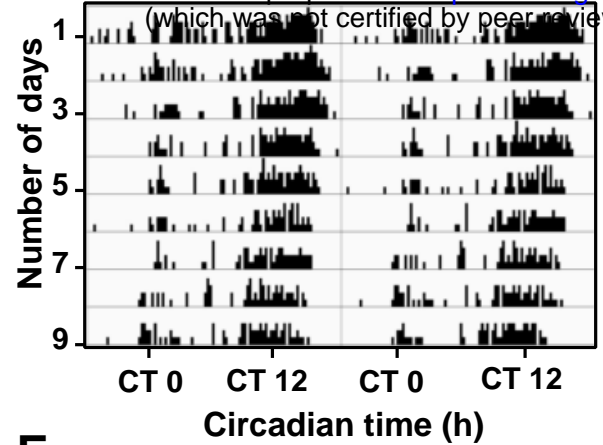

E

$0.75 \mathrm{mg} / \mathrm{mL}$ (T25.00hr)

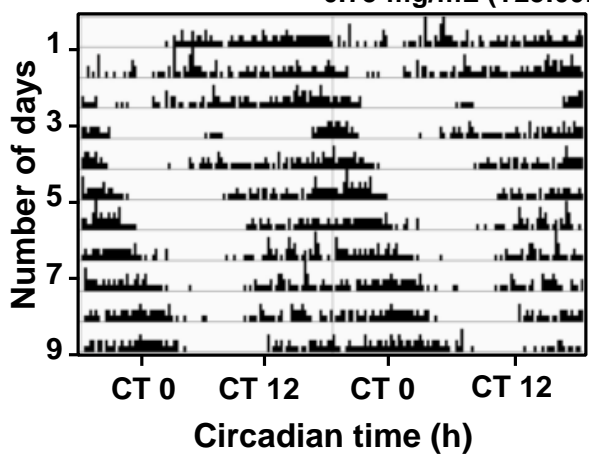

H

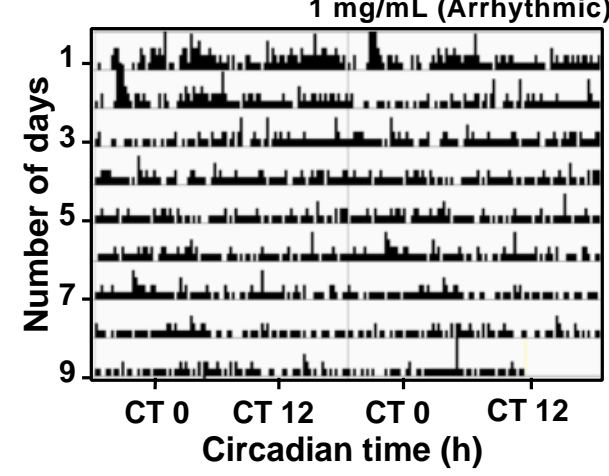

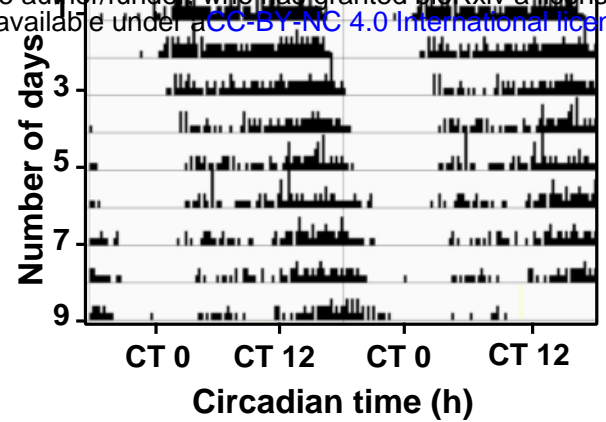

$F$

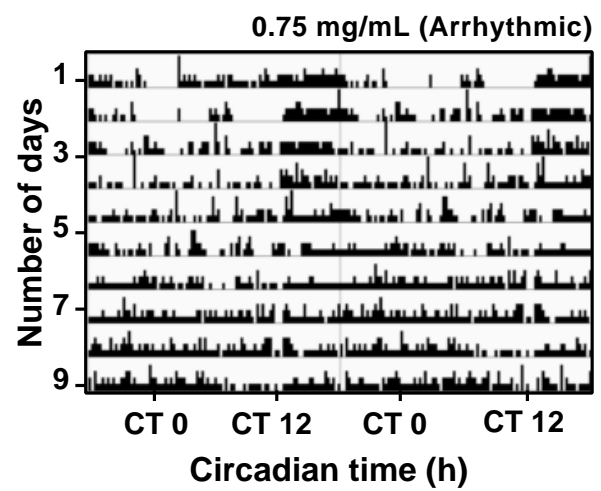

$\mathbf{J}$

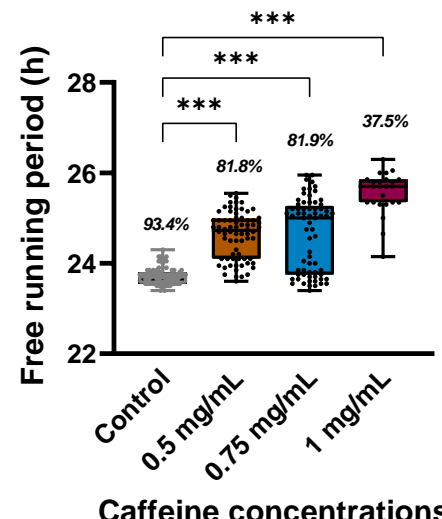

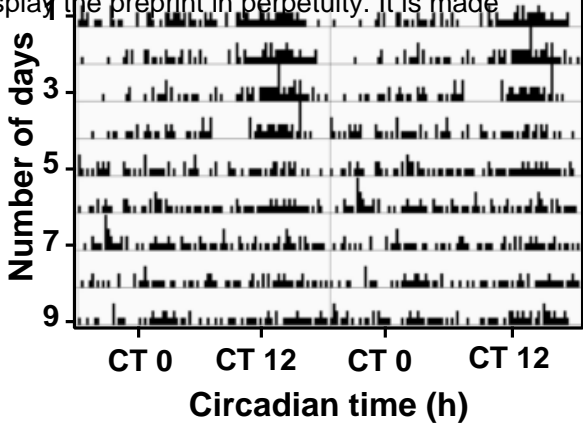

G

$1 \mathrm{mg} / \mathrm{mL}$ (T25.2hr)
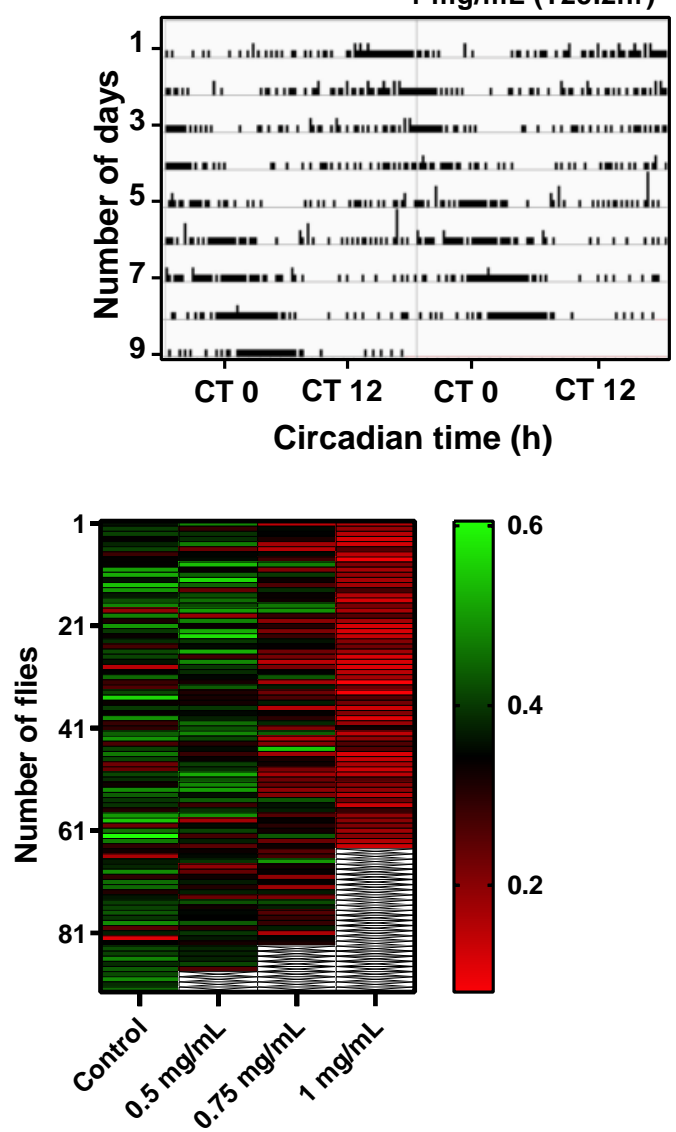


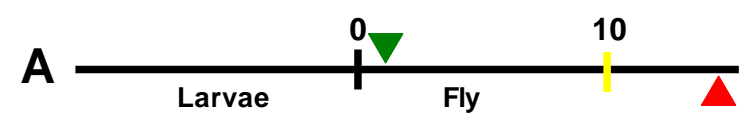

bioRxiv preprint dai(which was not certified by peer review) is the author/funder, who has granted bioRxiv a license to display the preprint in perpetuity. It is made

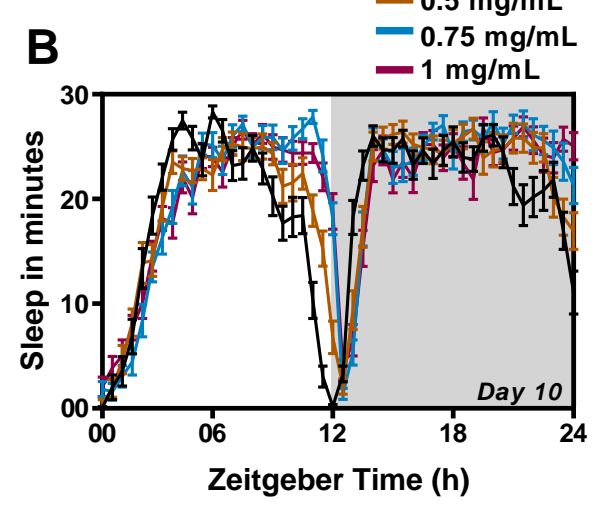

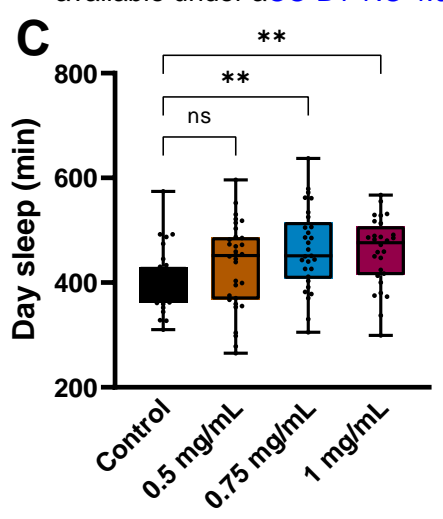

Caffeine concentrations

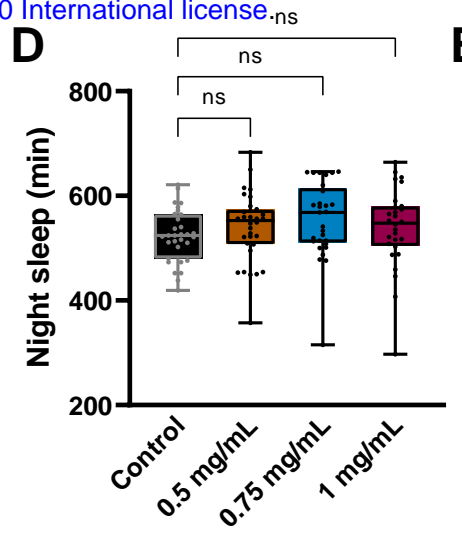

Caffeine concentrations

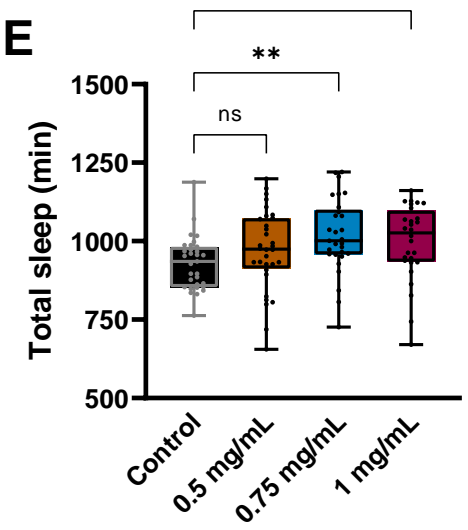

Caffeine concentrations

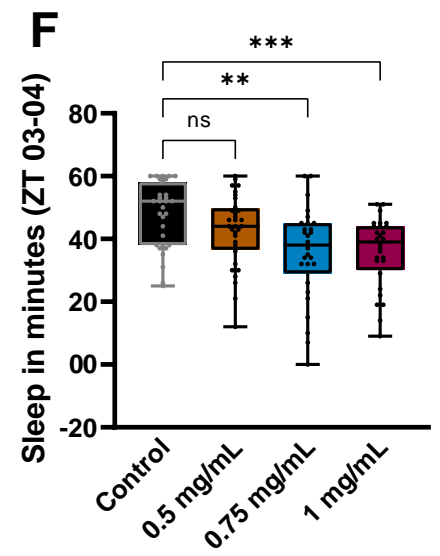

Caffeine concentrations
G

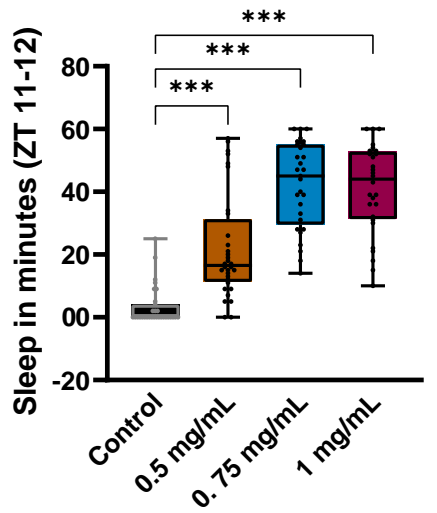

Caffeine concentrations
H

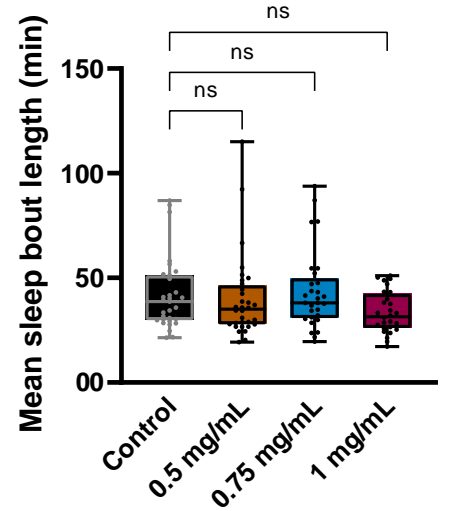

Caffeine concentrations
I

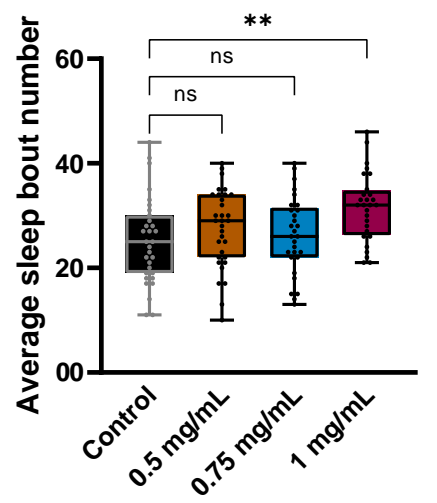

Caffeine concentrations

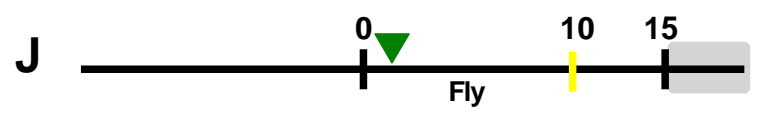

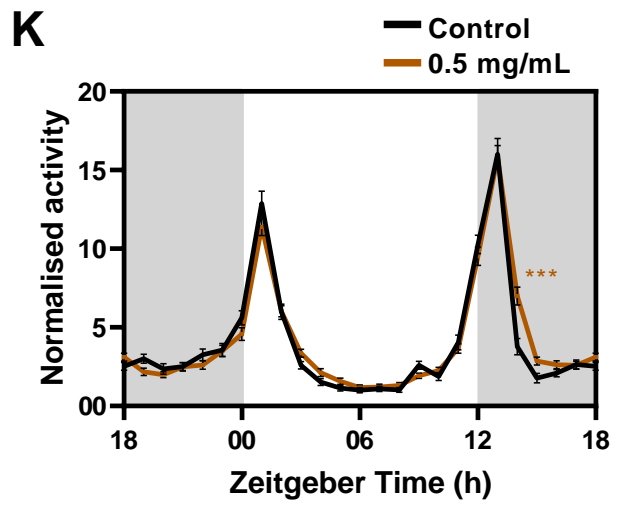

N

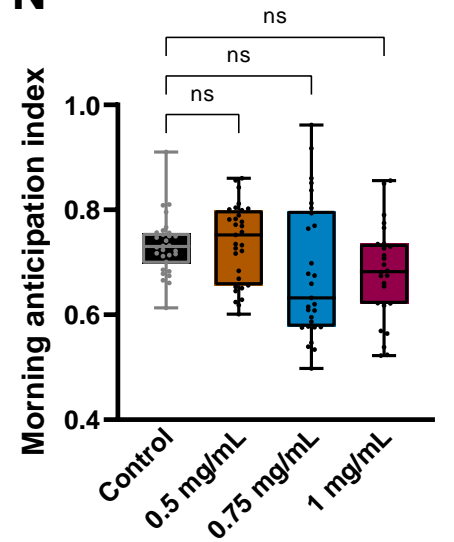

Caffeine concentrations

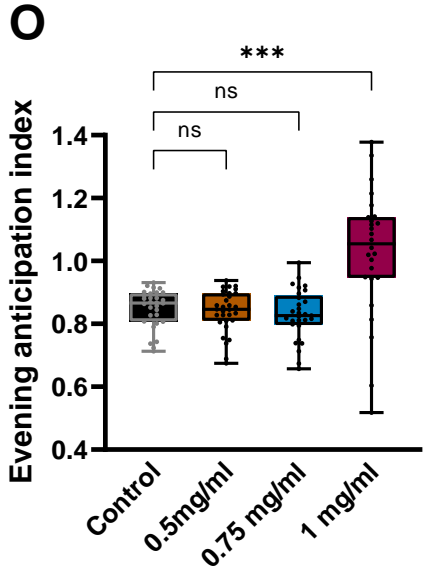

Caffeine concentrations

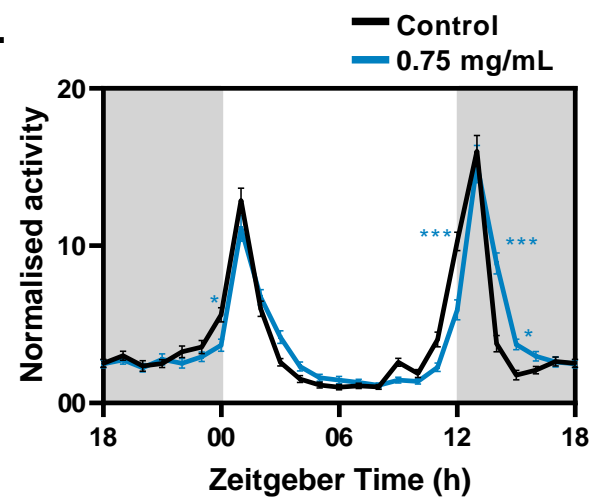

$\mathbf{P}$

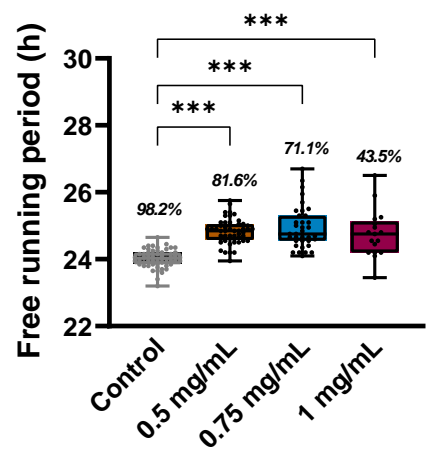

Caffeine concentrations

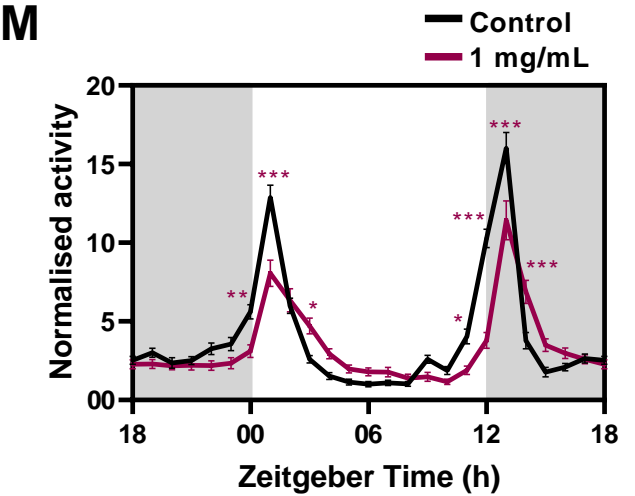

Q

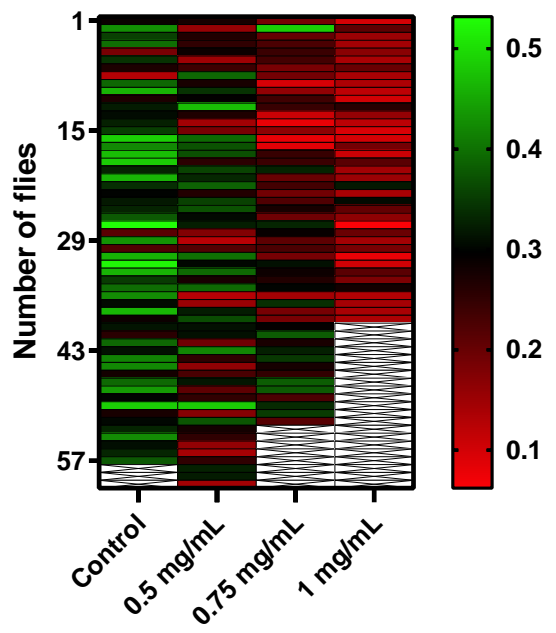

